\title{
Cryptocurrencies and blockchain. Overview and future perspectives
}

\author{
Helder Sebastião \\ Univ Coimbra, CeBER, Faculty of Economics, Coimbra, Portugal \\ Email: helderse@fe.uc.pt
}

Paulo Rupino da Cunha

Univ Coimbra, CISUC, Department of Informatics Engineering, Coimbra, Portugal

Email: rupino@dei.uc.pt

\author{
Pedro Godinho* \\ Univ Coimbra, CeBER, Faculty of Economics, Coimbra, Portugal \\ Email: pgodinho@fe.uc.pt \\ *Corresponding author
}

\begin{abstract}
This article presents an overview of the main developments of cryptocurrencies and discusses their future perspectives. First, it briefly reviews the history of cryptocurrencies since the creation of Bitcoin, presents the main market trends, and discusses the key features of cryptocurrencies in the context of blockchain. Second, it analyses current cryptocurrency projects, like the Libra project, and other applications of the blockchain technology. Third, it presents a systematic economics and financial literature review on cryptocurrencies. Fourth, it examines the challenges, benefits, and future perspectives of cryptocurrencies and blockchain technology, with a focus on the environmental issues and central bank digital currencies.
\end{abstract}

Keywords: Bitcoin; Blockchain; Cryptocurrencies; Digital Coins; Libra; Ethereum; Market Efficiency; Central Bank Digital Currencies; Survey

\section{Introduction}

Despite some initial scepticism, cryptocurrencies thrived in the last two decades, gaining an important place in the international financial landscape. The launch of Bitcoin futures contracts, in December 2017, by the Chicago Board Options Exchange (CBOE) and the Chicago Mercantile Exchange (CME), was symptomatic of the attempt of the traditional financial industry not to remain apart from this market trend. By now, the market capitalization of cryptocurrencies surpasses $\$ 200$ billion, which makes it one of the largest unregulated market in the world (Foley et al., 2019).

Arguably, even more important than the cryptocurrencies themselves, is the underlying technology - the blockchain. The World Economic Forum (WEF) includes this technology in the list of six Megatrends that will shape the world in the next decade (WEF, 2015). Others compare the current moment to that of the introduction of the World Wide Web. Then, as now, few could predict the extension of the disruptions that the new technology would cause (Mougayar, 2016). 
The main point of view that underlies this paper is that, although cryptocurrencies, as they stand today, have several issues that prevent them from being used as a generalized medium of payment, induce speculation and produce important negative environmental externalities, they also have the merit of being a real world-wide proof-of-concept of blockchain and digital money. As such, they have provided vital information for individuals, academic researchers from different scientific areas, private institutions, and regulators. The bulk of knowledge and experience of more than one decade, since the inception of Bitcoin, are the bases for improvements in the design and implementation of new cryptocurrencies, but, more importantly, to generally support the present demand for digitalization of economic processes and practices through applications of blockchain, and, specifically, the trend towards a future digital money economy. The literature review presented in the next sections, on which we support this thesis, puts into perspective the interactions between cryptocurrencies and blockchain, and their financial and economic implications. This approach is constructed on two main axes of analysis.

First, although cryptocurrencies and blockchain are intimately linked, they have been mostly treated separately in the literature. Blockchain has been mainly studied by experts in the fields of computer science, information systems, and cryptography, while cryptocurrencies, being tradable assets, have drawn the attention of economists. Since 2014 , the cryptocurrency literature approaching the issue from the economics and financial perspectives has been growing exponentially. This has been driven in part by the explosive price behaviour (and high media coverage), but also by the academic community's perception that the online exchanges are an excellent worldwide market laboratory, with a large number of interactors with different capacities, low entry costs and a huge amount of publicly available information. Although more focused on the financial economics perspective, this work also discusses blockchain, and the reasons why it is so disruptive.

Second, we acknowledge that there are many surveys on the technicalities and applications of blockchain (for instance, Ali et al., 2019; Casino et al., 2019; Dasgupta et al., 2019; Jaoude and Saade, 2019; Mohanta et al. 2019; Monrat et al., 2019; Morhaim, 2019; Taylor et al., 2019; Xu, 2019; Wang et al., 2019; Yaga et, 2019; Yang et al., 2019; just to name a few dated of 2019). Nevertheless, surveys on cryptocurrencies from an economics perspective are still scarce. Recently, authors such as Holub and Johnson (2018), Corbet et al. (2019c), Merediz-Sola and Bariviera (2019), Bariviera and MeredizSola (2020) and Giudici et al. (2020), have conducted efforts to systemize the economics literature and to provide bibliometric analyses on cryptocurrencies. This paper contributes to this stream of research, aiming at giving a comprehensive insight into the state-of-theart, highlighting common findings and conflicting results. This, in turn, will help to expose gaps in the literature and to formulate hypotheses for further research.

The remainder of the paper is organized as follows. Section 2 provides a brief historical overview of cryptocurrencies since the creation of Bitcoin, covering the dynamics of its prices and volumes, the main features of the blockchain technology and the basic historical trends in the market of cryptocurrencies. Section 3 presents a review on the determinants of the price of cryptocurrencies, its hedging and safe-haven properties, market efficiency, predictability and profitability, market connectedness, volatility spillovers and information flows. Section 4 discusses three main challenges that, in our point of view, will shape the future of cryptocurrencies and will have disruptive economic impacts at a global scale, namely the intensive energy consumption in the mining processes, the pervasive nature of the blockchain technology and the implementation of central bank digital currencies. 
Section 5 conducts a wrap-up exercise and enunciates several opinions on the future of cryptocurrencies, blockchain and digital money.

\section{A brief historical overview of cryptocurrencies}

\subsection{Bitcoin}

On October 31, 2008, someone under the pseudonym Satoshi Nakamoto, uploaded to a cryptography mailing list a whitepaper describing "a purely peer-to-peer version of electronic cash would allow online payments to be sent directly from one party to another without going through a financial institution" (Nakamoto, 2008). On January 3, 2009, Nakamoto created the Bitcoin network, based on open-source software that maintains a special decentralised public ledger, which became commonly known as blockchain, and created (mined) the first block in the chain (the genesis block). Table 1 presents the technical and economic features of Bitcoin.

Table 1 Technical features of Bitcoin

\begin{tabular}{|l|l|}
\hline Feature & Description \\
\hline Immaterial & $\begin{array}{l}\text { Electronic system based on cryptographic entities without any physical } \\
\text { representation or intrinsic value }\end{array}$ \\
\hline Decentralized & $\begin{array}{l}\text { Designed to be a peer-to-peer (P2P) payment system without the need for } \\
\text { a trusted third party }\end{array}$ \\
\hline Accessible & $\begin{array}{l}\text { Open source, so anyone with Internet access may download the software, } \\
\text { connect through it to the network and begin mining and transacting } \\
\text { Bitcoins }\end{array}$ \\
\hline Transparent & Information on all transactions on Bitcoins are public knowledge \\
\hline Integrity & Solves the double-spending problem \\
\hline Consensual & All the network manages the balances and transfers of Bitcoins \\
\hline Global & There are no geographic or fundamental economic barriers to its use \\
\hline Portable & $\begin{array}{l}\text { Practically any sum of Bitcoins can be carried on a flash drive or even } \\
\text { stored online }\end{array}$ \\
\hline Fast & $\begin{array}{l}\text { It takes less time to confirm a Bitcoin trade (30 minutes to 16 hours) than } \\
\text { it usually takes to do a normal bank transfer }\end{array}$ \\
\hline Cheap & Transfer costs are relatively low \\
\hline Irreversible & Bitcoin transactions cannot be reversed \\
\hline Immutable & Once recorded into the blockchain the trade cannot be modified \\
\hline Divisible & The smallest unit of a Bitcoin is called a satoshi (10-8 of a Bitcoin). \\
\hline Resilient & The network has been proven to be robust to attacks \\
\hline Pseudonymous & $\begin{array}{l}\text { The system does not identity of users, but discloses the addresses of their } \\
\text { wallets }\end{array}$ \\
\hline Limited supply & Bitcoin offer is capped at 21 million units \\
\hline
\end{tabular}

Before Bitcoin, there were other attempts to create virtual currencies (e-cash, hashcash, b-money, or bit gold, to name a few) but they did not thrive because they required a trusted third party to solve the double-spending problem (Narayanan and Clark, 2017). Bitcoin prevents it by using cryptography-based technology that dispenses with any intermediaries.

The USA subprime mortgage crisis in 2007-2010 generated a collective distrust against banks, monetary authorities, regulators, and politicians. This conjunctural turmoil created the conditions for raising the attention of the general public to Bitcoin. Since then, the 
supply of Bitcoins has increased at a predictable (slightly decreasing) rate. On the end of November 2012, the Bitcoin supply achieved half of its potential value and by December 2019 it was already more than $86 \%$ of the maximum supply (21 million BTC). Onexchange trading volume has also increased steadily. In 2014 the average daily volume was around 12.5 thousand Bitcoins, it more than doubled in 2015, reaching 29.7 thousand, in 2016 increased to 38.0 thousand, and in 2017 and 2018, boosted to 110.4 and 375.0 thousand, respectively. All these figures clearly show that Bitcoin has been the object of an increasing "public recognition". Additionally, the historical appreciation of Bitcoin has been quite remarkable. On May 22, 2010 Bitcoin was used for the first time in a real-world trade, to buy two pizzas (worth \$25) for 10'000BTC. In February 2011 Bitcoin reached the dollar parity $(1 \mathrm{BTC}=\$ 1$ ), and in May 2013, one BTC was worth more than $\$ 100$. See http://historyofBitcoin.org/ for a timeline that illustrates thoroughly the Bitcoin history. Figure 1 shows the evolution of the price of Bitcoin in USD, from January 01, 2014 to December 05, 2019.

Figure 1 Daily Bitcoin prices in USD (at 00:00:00 UTC) from January 01, 2014 to December 05, 2019. Data was collected from the CoinMarketCap website (https://coinmarketcap.com/).

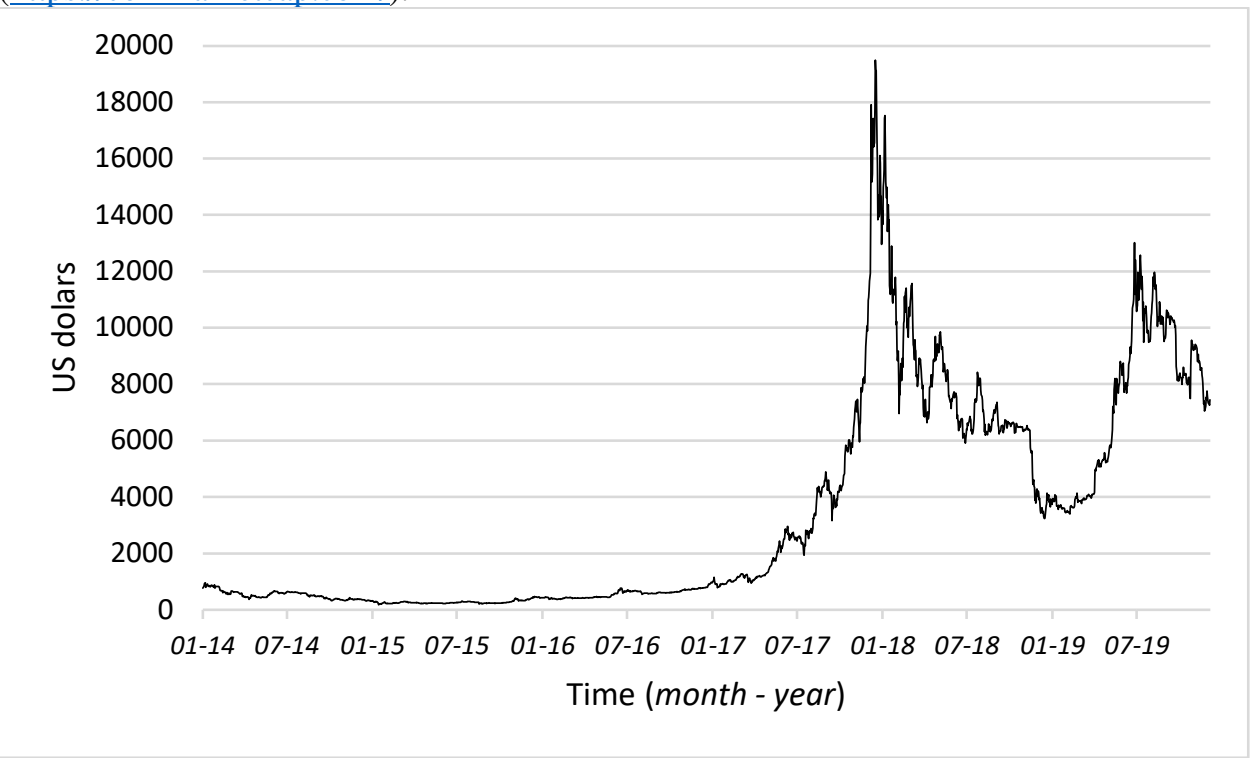

A "calm market" situation characterized the years of 2014 to 2016. Still, in 2016, the Bitcoin price increased from $\$ 771.4$ to $\$ 963.7$ - the overall return was roughly $25 \%$. Market conditions changed dramatically afterwards. In 2017, prices rose at increasing rates, exhibiting an explosive bubble-like behaviour. From January 01, 2017, until the peak on December 16, 2017, Bitcoin prices increased from \$998.3 to \$1'9497.4, resulting in a rate of return of more than 1'853\%. Clearly, during 2017 there was a lot of FOMO (Fear-OfMissing-Out) going on in the cryptocurrencies' market and, most probably, herding behaviour (Bouri et al., 2019a; Vidal-Tomás et al., 2019; Stavroyiannis and Babalos, 2019). In 2018, Bitcoin prices fell rapidly. In the first quarter of 2018, the Bitcoin price dropped to half of its price on the beginning of the year, and in just two weeks, from November 12, 2018, to November 26, 2018, it dropped around $-40.7 \%$, reaching the oneyear minimum of \$3'779.13. 
Although Bitcoin futures were already available for trading in Bitmex - the largest unregulated Bitcoin derivatives exchange - since May 13, 2016 (see Alexander et al., 2019, for a comprehensive study on these futures contracts), the severe bear market was associated with the creation of Bitcoin futures in December 2017, by the CBOE and the CME (Liu et al., 2019). If, on the one hand, these derivatives may provide an effective way to hedge the price risk of Bitcoin and even other major cryptocurrencies (Sebastião and Godinho, 2019) and enhance price discovery (Kapar and Olmo, 2019; Akyildirim et al., 2019); on the other hand they also allow pessimists to enter the market, betting against Bitcoin in a regulated market with lower margin requirements (Hale et al., 2018; Baur and Dimpfl, 2019).

The second quarter of 2019 experienced another bull price rally, with prices increasing from \$4'158.2 on April 01, 2019 to \$12'573.8 on July 09, 2019 (an increase of 202.4\%). From that point on, Bitcoin prices began a new negative trend, and on December 05, 2019 (the end of the sample), Bitcoin price was less than $\$ 7^{\prime} 500$.

Table 2 presents some summary statistics of the daily log-returns of Bitcoin, crude oil, S\&P 500 stock index, gold, USD/EUR official exchange rate and S\&P 500 bond index from January 02, 2004 to December 02, 2019.

Table 2 Summary statistics of daily log-returns of Bitcoin and other 5 assets (January 02, 2014 - December 02, 2019)

\begin{tabular}{|l|c|c|c|c|c|c|}
\hline & Bitcoin & Crude Oil & S\&P 500 & Gold & USD/EUR & Bonds \\
\hline No. observations & 2160 & 1487 & 1493 & 1495 & 1513 & 1499 \\
\hline Mean (\%) & 0.1024 & -0.0357 & $0.0355^{*}$ & 0.0119 & -0.0142 & $0.0191 * * *$ \\
\hline Median (\%) & 0.1477 & 0.0193 & 0.0504 & -0.0042 & -0.0178 & 0.0277 \\
\hline Minimum (\%) & -23.757 & -11.126 & -4.1843 & -2.7324 & -3.6820 & -1.2287 \\
\hline Maximum (\%) & 22.512 & 14.176 & 4.8403 & 3.7297 & 2.4664 & 0.7478 \\
\hline St. Dev. (\%) & 3.9132 & 2.3169 & 0.8298 & 0.7776 & 0.5011 & 0.2288 \\
\hline Skewness & -0.3463 & 0.1909 & -0.5140 & 0.1969 & -0.2032 & -0.3093 \\
\hline Exc. kurtosis & 5.4202 & 3.2017 & 3.6719 & 1.2027 & 4.3625 & 1.1084 \\
\hline$\rho(1)$ & -0.0032 & $-0.0687 * * *$ & -0.0199 & 0.0184 & -0.0026 & $-0.0499 *$ \\
\hline
\end{tabular}

Notes: Data on Bitcoin was obtained from the CoinMarketCap website. Crude Oil refers to the dollar price per barrel in the West Texas Intermediate (WTI), Gold is the gold fixing dollar price per troy ounce at 10:30 a.m. (London time) in the London Bullion Market. These data were obtained from the FRED database of the Federal Reserve Bank of St. Louis. Data on USD/EUR official exchange rate was retrieved from the European Central Bank site. Bond is the S\&P 500 Bond Index obtained from the S\&P Dow Jones Indices website. The significance of the mean returns and first-order autocorrelations, $\rho(1)$, was tested using HAC standard errors and Bartlett standard errors, respectively. Significance at the $1 \%, 5 \%$ and $10 \%$ level is denoted by “*”, “**” and “***”, respectively.

Bitcoin trades around the clock, 24/7, while other markets are closed on weekends and holidays, hence the larger number of observations. Bitcoin daily mean return $(0.10 \%)$ was far higher than the daily mean returns of the other assets, but, most importantly, Bitcoin was more volatile, even than crude oil, which is one of the most volatile assets in the world. The standard deviation of Bitcoin returns was $3.91 \%, 69 \%$ higher than the standard deviation of crude oil, and more than 7 times higher than the standard deviation of USD/EUR exchange rate. Bitcoin daily returns ranged from $-23.78 \%$ to $22.51 \%$, while the 
crude oil daily returns only ranged from $-11.13 \%$ to $14.18 \%$, and other assets only presented one-digit percentage minimum and maximum returns. Bitcoin returns had negative skewness and higher excess kurtosis than the other assets and no significant firstorder autocorrelation. These features of Bitcoin, namely high volatility, extreme short-run movements (jumps), and bubble-like behaviour have been extensively documented in the literature (see, for instance, Cheung et al., 2015; Cheah and Fry, 2015; Dwyer, 2015; Yermack, 2015; Blau, 2017; Baur et al., 2018; Gkillas and Katsiampa, 2018; Cagli, 2019).

\subsection{Blockchain: A disruptive technology}

The technology underlying Bitcoin and most of other cryptocurrencies is known as blockchain. The key component of blockchain is a digital ledger, where the transactions among users are recorded. Since no central authority exists, this ledger is replicated among the participants (nodes) in the network, who collaboratively maintain it using dedicated software (Swan, 2015; Iansiti and Lakhani, 2017; Yaga et al., 2019), thus increasing transparency and resiliency (Berkley, 2015). More specifically, the ledger is composed of blocks that are cryptographically linked together - hence the name blockchain. As digitally signed transactions occur, they are grouped into new blocks that will be appended to the existing chain, preserving the full transactional history and enabling full traceability of the digital entities. The use of cryptographic mechanisms to protect the integrity of the ledger causes illegitimate changes in an existing block to be evident, invalidating them and all subsequent blocks. This means that an attempted forging would have to rewrite the whole ledger from the tampered block onwards. Additionally, it would have to succeed against the independent verifications and validations of the other network nodes, who own their copies of the ledger and only change it after a consensus is reached using a special algorithm. For these reasons, blockchains are said to be tamper-evident and tamperresistant, or, as commonly referred, immutable. The data in the ledger is attestable. These characteristics are the cornerstone of trust when transacting with anonymous parties (Beck et al., 2018; Yaga et al., 2019).

The nodes are, thus, critical in policing and maintaining the blockchain on which the Bitcoin network rests. That task requires resources, such as significant processing power (that causes non-negligible electricity consumption), storage and bandwidth. To ensure their sustainable commitment to the required self-regulation and discourage malicious behaviour, appropriate value propositions exist. Nodes that participate in the process of appending new blocks to the ledger (the so-called miners) are automatically rewarded in Bitcoins by the underlying software (Narayanan et al., 2016; Yaga et al., 2019).

In the Bitcoin network, the users are pseudonymous, meaning that their account numbers are known, but no link exists to their real-world identity. New accounts can be created without any identification or authorization, in contrast with the mandatory Know Your Customer (KYC) procedures required by traditional financial organizations (Lootsma, 2017). However, pseudonymity is not required in all blockchain-based systems. In fact, blockchains can be classified into two groups: permissionless and permissioned. The former, like the Bitcoin network, allows anyone to become a node without needing permission from any authority. Such actors gain full access to the ledger and participate in the process of maintaining it. To prevent malicious behaviour from such anonymous actors, the consensus mechanisms used in these cases typically require participants to expend significant resources to discourage foul play and reward them in the native cryptocurrency for conformance with the rules. In the case of Bitcoin, the consensus on who will append the next block to the chain is reached using the Proof of Work (PoW) algorithm. The first 
node to solve a specific computationally intensive puzzle will earn this right. To do so, however, it will incur in substantial electricity consumption. More recently, other permissionless blockchains have considered alternative algorithms that are eco-friendlier (Zheng et al., 2017). One such example is the Proof of Stake (PoS), which is based on the idea that “(...) the more stake a user has invested into the system [often an amount of cryptocurrency], the more likely they will want the system to succeed, and the less likely they will want to subvert it." (Yaga et al., 2019). Thus, actors with a higher stake are more likely to append new blocks to the ledger.

Permissioned blockchains, on the other hand, require identification and authorization of candidates by some authority (an organization or a consortium), thus enabling finegrained control over which participants can read and write the ledger and issue transactions. Since participants are known, some basic level of trust among them already exists, enabling consensus algorithms to be computationally lighter and thus faster and more electricityefficient, such as Round Robin, Proof of Authority, Proof of Elapsed Time, among others (Castor, 2017). Misbehaviour by participants can be handled by revoking access and using traditional legal means (Yaga et al., 2019).

Another important concept is that of smart contracts (Swan, 2015). These are computer programs that encode contractual agreements and are stored on the blockchain - thus becoming tamper-evident and tamper-resistant. They execute automatically as part of a transaction. For example, they may “(...) encapsulate the terms and conditions of travel insurance, which may be executed automatically when, for example, a flight is delayed by more than six hours." (Gupta, 2017). This automatic enforcement of the agreed-upon rules further adds to the trust among parties, by removing uncertainty about any of them fulfilling their contractual obligations. Although present in the original Bitcoin blockchain in a limited capacity (Bartoletti and Pompianu, 2017), smart contracts, originally introduced by Szabo (1994, 1997), were popularized by Ethereum (Ethereum, 2019), which provides a Touring-complete programming language, meaning that it can be used to solve any possible computational problem.

\subsection{The expanding universe of cryptocurrencies and online exchanges}

The rapid market capitalization growth of Bitcoin and its price appreciation led to the emergence of a large number of other cryptocurrencies that, most of the times, differ from Bitcoin in just some parameters (block time, currency supply, and issuance scheme). Litecoin was launch on October 2011, Ripple begun trading in the beginning of 2013, Tether and Ethereum (ETH) were launched in 2015, and, on August 1, 2017, Bitcoin Cash was created as a "sort of upgrade" of the Bitcoin system, just to name a few of the most relevant altcoins in terms of market capitalization and media coverage. However, referring only to these most important cryptocurrencies gives a misleading idea on what has been the dynamics of the cryptocurrency market. In fact, the number of new cryptocurrencies increased at an impressive rate. According to CoinMarketCap, the number of cryptocurrencies reached almost 4 thousand in December 2019. The overall cryptocurrency market capitalization now exceeds $\$ 200$ billion, but Bitcoin remains the most important cryptocurrency. The Bitcoin dominance (i.e. the ratio of Bitcoin market capitalization to the total cryptocurrency market capitalization) was above $80 \%$ from 2013 to the first quarter of 2017. It decreased sharply in the second quarter of 2017 and stayed at around $40 \%$ in the following year. It began increasing again since March 2018 to slightly above $65 \%$. 
On June 18, 2018, a consortium led by Facebook, named the Libra Association, announced the plans for a cryptocurrency called Libra. Given the size of the Facebook user base and the relevance of other founding members of the association, Libra promised to become a major player in the cryptocurrency landscape and to contribute to legitimize cryptocurrencies as a whole. Libra aimed to be a "simple global currency and financial infrastructure that empowers billions of people" and create a more inclusive financial system (Libra Association, 2019, p. 3). For that purpose, Libra is composed by three parts: a secure and scalable blockchain, a reserve of assets designed to give it an intrinsic value and avoid wild fluctuations in value, and the independent Libra Association that will govern Libra and evolve the Libra ecosystem.

There are significant potential benefits to a cryptocurrency developed along the lines of the Libra proposal. Schmeling (2019) points out the provision of a fast and cheap payment system, giving a store of value to the residents of countries with unstable currencies, a disciplining effect on the actions of national central banks, and the possibility of the blockchain-based ledger making it easier to track money-laundering activities. However, several authors have highlighted important risks associated with Libra. Abraham and Guegan (2019) analyse these risks, dividing them into political risks (for example, Libra may have a large influence in the global financial system), financial risks (including, e.g., systemic risks related to situations similar to bank runs in which a large number of users decide to change their Libra to fiat currencies), economic risks (like the creation of an oligopolistic market or difficulties associated with the taxation of Libra payments), technological risks (like cyberattacks, fraud or the failure of the Libra protocol) and ethic and regulatory risks (like the possibility of Libra having control over a large part of the world population and questions related to data property). Groß et al. (2019) also discuss the high risk associated with a collective loss of confidence in the Libra Association, which might lead to the exchange of sizeable quantities of Libra into fiat currencies in case, for example, of a data scandal, and the possibility of a relative loss of importance of traditional national banking systems. In the same line, Brühl (2019) and Schmeling (2019) discuss the ways Libra might undermine the effectiveness of monetary policy actions by central banks. The potential risks associated with the Libra project have led to several representatives of central banks and regulatory entities raising concerns about the project (Brühl, 2019). Meanwhile, several founding members of Libra have left the association, and even Facebook seems to be shifting its Libra plans. In March 2020, it was reported that Facebook no longer intended to make the Libra cryptocurrency the centrepiece of its digital payments strategy and, instead, it would support government-backed currencies, like the US dollar and the euro, alongside with Libra, in its digital wallet (Heath, 2020; Statt, 2020).

The first online exchange - Mt.Gox - emerged in 2010. In the following two years, Mt.Gox kept its leader position, holding a market share of more than $80 \%$ (Brandvold et al., 2015). Later on, Bitstamp, BTC-e, and Bitfinex gained prominence and, in the second half of 2013, these three exchanges held more than $50 \%$ of USD/BTC market share (Sebastião et al., 2017). In the following years, the number of cryptocurrency online exchanges increase rapidly and, according to CoinMarketCap, there were more than 20.5 thousand online exchanges in December 2019. But still, the industry kept fairly concentrated, at least in what concerns to Bitcoin, with just 8 exchanges (Bitfinex, Bitstamp, Bitx, Btce, Coinbase, Kraken, Itbit, Okcoin) accumulating roughly $90 \%$ of the trading volume since 2014 (see https://data.Bitcoinity.org).

There is clear evidence that Bitcoin prices in these multiple online exchanges are not completely arbitraged away, even between those exchanges with higher market shares 
(Pieters and Vivanco 2017; Makarov and Schoar, 2019). Consequently, transmission of information and volatility spillovers between exchanges can last for several hours or even days, and price discovery may occur at different paces (Brandvold et al., 2015; Sebastião et al., 2017; Pagnottoni, and Dimpfl, 2019).

\section{A brief review of financial and economics literature on cryptocurrencies}

\subsection{Determinants of cryptocurrencies price and its hedging and safe-haven properties}

Cryptocurrencies have no legal tender; therefore, their acceptance is based on user confidence, but, still, one may consider that they may serve as a medium of exchange in specific contexts. However, cryptocurrencies do not yet possess all the properties and features usually attributed to money. Cryptocurrencies provide an inferior service as a unit of account for tangible assets and services and are certainly not a good way to store nominal or real value due to their high volatility (Yermack, 2015). At most, cryptocurrencies can be viewed as a new kind of tradable speculative asset, which can work as an imperfect substitute for traditional currencies, or as a "synthetic commodity money" that resembles fiat money in having no nonmonetary value, but also resembling commodity money in being not just contingently but absolutely scarce (Selgin, 2015). Some authors are peremptory in questioning the motivations behind the implementation of Bitcoin and highlight the resemblance of its exchange activities to pure speculative trading (Glaser et al., 2014; Baeck and Elbeck; 2015). The basic idea that Bitcoin and other cryptocurrencies may be a purely speculative asset triggered an important strand of research aiming, on the one hand, to assess the relationships between cryptocurrencies and macroeconomic and financial variables, and on the other hand to examine its price determinants, which most probably would be found within the investors' behavioural sphere.

Kristoufek (2013) finds a high correlation between the number of Bitcoin search queries on Google Trends, the number of Wikipedia views on Bitcoin, and Bitcoin prices. Kristoufek (2015) reinforces the previous findings and does not find any meaningful correlation with fundamental variables such as the Financial Stress Index (FSI) and the gold price in Swiss francs. Instead, he argues that the Bitcoin price cannot be explained by economic theory hence is driven by speculative investments. Bouoiyour and Selmi (2014) regress the Bitcoin price on several variables, such as the market price of gold, Google searches, and the velocity of Bitcoin measured by transaction data. The authors find that only the lagged Google searches were significant at the $1 \%$ level. Polasik et al. (2015) also show that Bitcoin price formation is primarily the result of its popularity and the transactional needs of its users, hence concluding that Bitcoin returns are mainly driven by news volume, news sentiment, and the number of traded Bitcoins. Ciaian et al. (2016) find that market forces and investor attractiveness are the main drivers of Bitcoin prices, and there is no evidence that macro-financial developments have any impact on Bitcoin in the long run. Kim et al. (2016) employ user comments in online cryptocurrency communities to predict fluctuations in the daily prices and transactions of Bitcoin, Ethereum, and Ripple, with positive results, especially for Bitcoin. Zhu et al. (2017) show that economic factors such as Customer Price Index, Dow Jones Industry Average, Federal Funds Rate and gold price, and, most especially an US Dollar Index, influence monthly Bitcoin prices. Li and Wang (2017) find that in early market stages, Bitcoin prices were driven by speculative 
investment and deviated from economic fundamentals. As the market matured, the price dynamics followed more closely the changes in the economic factors, such as US money supply, gross domestic product, inflation, and interest rates. Phillips and Gorse (2017) show that hidden Markov models based on the behaviour of novel online social media indicators provide the basis for successful trading strategies on several cryptocurrencies. Baur et al. (2018) find that Bitcoin is uncorrelated with traditional asset classes such as stocks, bonds, exchange rates and commodities, both in normal times and in periods of financial turmoil. Corbet et al. (2018) find that Bitcoin, Ripple and Litecoin prices are unrelated to several economic and financial variables in the time and frequency domains. Dastgir et al. (2019) study the causal relationship between Bitcoin attention (measured by Google Trends) and Bitcoin returns from 2013 to 2017. They observe a bi-directional causal relationship, except for the central distributions from $40 \%$ to $80 \%$. Phillips and Gorse (2018) investigate if the relationships between online and social media factors and the prices of Bitcoin, Ethereum, Litecoin and Monero depend on the market regime (bubbles versus other events). The authors use wavelet coherence as a metric for the comovement between cryptocurrency prices and those factors, finding that medium-term positive correlations strengthen significantly during bubble-like regimes, while short-term relationships appear to be caused by particular market events (such as hacks or security breaches).

Built upon the finding that Bitcoin and other cryptocurrencies are unrelated with most financial and macroeconomic variables, several papers investigate their diversification, hedging, and safe-haven (as traditionally defined by its correlation with other assets during times of market stress) properties. Dyhrberg (2016a) uses an asymmetric GARCH to show that Bitcoin may be useful in risk management as it can be classified as something in between USD and gold on a scale ranging from a pure medium of exchange to a pure store of value asset. Also using an asymmetric GARCH, Dyhrberg (2016b) argues that Bitcoin can be used as a hedge against stocks in the FTSE index and as a hedge against the USD in the short-term, thereby possessing some of the same hedging abilities of gold. Baur et al. (2018) refuted the work of Dyhrberg (2016a), showing that Bitcoin exhibits distinctively different return, volatility and correlation features when compared to other assets, including gold and the USD. Bouri et al. (2017) also document a weak connection between Bitcoin and other financial variables, such as major world stock indices, bonds, oil, gold, a general commodity index, and a USD index. As such, Bitcoin can act as a hedge and safe-haven for these assets, although it is more suitable for diversification purposes. Guesmi et al. (2019) show that the inclusion of Bitcoin in hedging strategies involving gold, oil, and equities considerably reduces the risk of the portfolio. Fang et al. (2019) find that global economic policy uncertainty has a significant negative impact on the Bitcoin-bonds correlation and a positive impact on both Bitcoin-equities and Bitcoin-commodities correlations, suggesting the possibility of Bitcoin acting as a hedge under specific economic uncertainty conditions. Chan et al. (2019) find that Bitcoin is an effective strong hedge for stock indices, such as the Euro STOXX, Nikkei, Shanghai A-Share, S\&P 500, and the TSX Index, at a monthly frequency. However, daily and weekly returns do not show strong hedge properties. Urquhart and Zhang (2019) assess the relationship between Bitcoin and currencies at the hourly frequency and conclude that Bitcoin does act as an intraday hedge, diversifier, and safe-haven for certain currencies. Tzouvanas et al. (2019) find that momentum portfolios of cryptocurrencies not only offer diversification benefits 
but also can be a hedge and safe-haven for traditional assets. Smales (2019) looks into this issue from another perspective. The author points out that research in the safe-haven properties of Bitcoin neglects other attributes of assets that are important to investors during periods of crisis. Bitcoin is more volatile, less liquid, and costlier to transact (in terms of time and fees) than other assets (including gold - the traditional safe-haven asset), even in normal market conditions. As such, until the market matures, Bitcoin should not be considered a safe-haven asset.

\subsection{Market efficiency, predictability, and profitability}

The informational efficiency of cryptocurrencies has been scrutinized in several papers (see Kyriazis, 2019, for a survey on the topic). Urquhart (2016) and Bariviera (2017) conclude that Bitcoin is inefficient, while Nadarajah and Chu (2017) and Tiwari et al. (2018), reach the opposite conclusion. Vidal-Tomás and Ibañez (2018) argue that Bitcoin became more efficient over time concerning its own events, but it is not affected by monetary policy news. Jiang et al. (2018) point out that Bitcoin exhibits long-term memory, a high degree of inefficiency, and that did not become more efficient over time. Zargar and Kumar (2019) show that Bitcoin is informationally inefficient at high frequencies $(15,30$, 60 and $120 \mathrm{~min}$ ). Kristoufek (2018) finds strong evidence that Bitcoin denominated in USD and CNY remained mostly inefficient between 2010 and 2017, but it showed a high degree of efficiency during cooling-downs after bubble-like price surges. Other papers look into this issue considering other cryptocurrencies than Bitcoin. Charfeddine and Maouchi (2019) show that the returns and volatility series of Bitcoin, Litecoin, and Ripple exhibit a true Long Range Dependence, while, for Ethereum, this dependence is only supported for the volatility series, hence the authors confirm the inefficiency of all the considered markets, except Ethereum. Kristoufek and Vosvrda (2019) show that Bitcoin, DASH, Litecoin, Monero, Ripple, and Stellar were unanimously inefficient, with Ethereum and Litecoin being the least efficient and DASH being the most efficient. Hu et al. (2019) use several panel tests on 31 top market-cap cryptocurrencies which indicate market inefficiency. Le Tran and Leirvik (2019) show that the level of market-efficiency in the five largest cryptocurrencies is highly time-varying. Specifically, before 2017, cryptocurrency markets were mostly inefficient but became more efficient over time in the period 2017-2019. On average, Litecoin was the most efficient cryptocurrency and Ripple the least efficient one.

In essence, this strand of the literature points out that the cryptocurrency market is inefficient, but, as it matures, is in the process of moving towards efficiency. This maturation effect on informational efficiency may be due to investor's learning processes, however, it is most probably due to an increase in market liquidity, which in turn reduces the level of predictability and persistence in the returns of cryptocurrencies, especially of Bitcoin. For instance, Brauneis and Mestel (2018), as well as Wei (2018), document that cryptocurrencies are less predictable as liquidity increases, both through time and on a cross-sectional basis. For well-established cryptocurrencies, such as Bitcoin and Ethereum, this liquidity effect should be more pronounced during stressed periods, because then investors' trading preferences will favour these cryptocurrencies to the detriment of lesserknown ones (Kyriazis and Prassa, 2019).

The link between returns and other market indicators, namely trading volume, of cryptocurrencies is analysed in some papers, with mixed results. Koutmos (2018a) argues 
that there are strong linkages between Bitcoin returns and its transaction activity (measured by number of transactions and unique addresses), with returns explaining relatively more of the variation in transaction activity than vice versa. Balcilar et al. (2017) conclude that volume Granger-causes returns over the quantile range of 0.25 to 0.75 . However, the test fails to reject the null hypothesis that volume does not Granger-cause volatility over the entire conditional distribution. Bouri et al. (2019b) somehow contradict this result. Using a copula-quantile causality approach, the authors find that trading volume Granger-causes extreme negative and positive returns. Aalborg et al. (2019) use daily and weekly data to investigate the predictability of returns, volatility, and trading volume of Bitcoin, showing that although lagged trading volume is significant at the 5\% level when predicting daily returns, this significance fades away when predicting weekly returns. Wang et al. (2019b) look at trading volume and volatility of Bitcoin denominated in 15 foreign currencies across more than 60 trading platforms and conclude that the two variables are contemporaneously negatively correlated and exhibit a significant lead-lag relationship. El Alaoui et al. (2018) study the daily price-volume correlation in the Bitcoin market via the multifractal detrended cross-correlations analysis (MF-DCCA). The results suggest that changes in prices and trading volume may interact in a nonlinear way. Beneki et al. (2019) apply a multivariate BEKK-GARCH and VAR impulse responses to daily data on Bitcoin and Ethereum, finding that the volume of a given cryptocurrency has a positive effect on that cryptocurrency's returns and a negative impact on the returns of the other cryptocurrency.

A closer look into the predictability of cryptocurrencies' returns is provided by Caporale et al. (2018) and Catania et al. (2019). In the first paper, the authors use two different long-memory methods (R/S analysis and fractional integration) to show that Bitcoin, Litecoin, Ripple and Dash exhibit persistence over the sample period 2013-2017, hence trend trading strategies can be used to generate abnormal returns in these cryptocurrencies. The second paper compares several alternative univariate and multivariate models, with and without exogenous variables, for point and density forecasting of daily closing prices of Bitcoin, Ethereum, Litecoin, and Ripple for the period from August 08, 2015 to December 28, 2017. These models and their combinations are then compared with the forecasts from autoregressive models of order 1 with time-varying volatility driven by Exponential Weighted Moving Averages (AR(1)-EWMA). The features space includes international stock indexes, commodity prices, interest rates, VIX and lags of the prices of cryptocurrencies. The combination of a large set of predictors increased the point forecast accuracy but did not improve the density forecasting, and the multivariate schemes offered statistically significant gains at all horizons ( 1 to 7 days ahead) when the complete distribution was predicted.

Other authors have investigated trading strategies with cryptocurrencies. Grobys and Sapkota (2019) study momentum trading strategies implemented among 143 cryptocurrencies over the 2014-2018 period without finding any evidence of significant momentum payoffs. Gerritsen et al. (2019) apply seven trend-following indicators to the Bitcoin daily price from July 2010 to January 2019, finding that the trading range breakout outperforms the buy-and-hold strategy in terms of Sharpe ratio. Corbet et al. (2019a) analyse various technical trading rules using high-frequency Bitcoin returns, concluding that the variable-length moving average rule is the most profitable trading strategy for Bitcoin. Miller et al. (2019) use an automatic price pattern search procedure (nonparametric regression method of smoothing splines) for Bitcoin, based on 1-min prices 
from GDAX, and find that strategies based on certain technical analysis patterns yield returns that significantly exceed the results of unconditional trading strategies. Grobys et al. (2019) study simple moving average trading strategies employing daily prices on the eleven most-traded cryptocurrencies in the 2016-2018 period. The authors find that a 20day variable moving average strategy is successful. Specifically, excluding Bitcoin, the technical trading rule generates an excess return of $8.76 \%$ per year after controlling for the average market return. However, none of these studies considers trading costs, execution delays or other market frictions, which may raise questions concerning the profitability of these strategies.

The forecastability of cryptocurrencies' price movements and the profitability of trading strategies have also been addressed using Machine Learning tools, such as Binomial Logistic Regressions (Madan et al., 2015), Random Forests (Madan et al., 2015; Vo and Yost-Bremm, 2018; Xiaolei et al., 2018), Decision Trees (Huang et al., 2018; Xiaolei et al., 2018; Alessandretti et al., 2018), Support Vector Machines (Żbikowski, 2016; Xiaolei et al., 2018; de Souza et al., 2019; Mallqui and Fernandes, 2019), and Artificial Neural Networks (Jiang and Liang, 2017, McNally et al., 2018; Jang and Lee, 2018; Nakano et al., 2018; de Souza et al., 2019; Mallqui and Fernandes, 2019, Lahmiri and Bekiros 2019), particularly Long Short-Term Memory Networks (McNally et al., 2018, Alessandretti et al., 2018; Lahmiri and Bekiros, 2019). Most of these papers use Bitcoin daily price data, but some of them use high-frequency data or data on other cryptocurrencies. The input information sets of the models vary considerably and include different combinations of transaction prices, Open-Low-High-Close prices, technical indicators built on those prices (such as Moving Average Convergence-Divergence, Stochastic Oscillators and On-Balance Volume), features of the blockchain (e.g. difficulty, hash rate, volume of trades, total transaction fees, number of transactions, cost per transaction) and even other financial and macroeconomic variables (e.g. stock indexes, gold, VIX, exchange rates and oil prices).

Overall, this research concludes that the Machine Learning models have high levels of accuracy and improve the predictability of returns (lower Root Mean Square Error), overperforming competing models such as ARIMAs and Exponential Moving Averages. Some of these studies also compare the performance of trading strategies devised upon these Machine Learning models and buy-and-hold passive strategies (with and without trading costs). The unanimous conclusion is that Machine Learning-based strategies are better in terms of overall cumulative return, volatility, and Sharpe ratio. In summary, this strand of the literature points out that, independently of the data period and frequency, investment horizon, input set and method used to define the trading strategies, the prices (or returns) of the main cryptocurrencies are predictable. However, most of these studies cover a period of a steady upward price trend, and often do not consider trading costs, liquidity constraints, execution delays and short-selling restrictions. So, it remains to be seen if these results still hold in different market conditions.

\subsection{Market connectedness, volatility spillovers and information flows}

Arguably, cryptocurrencies, at least the ones with higher market capitalization, are close substitutes, sharing the same underlying driving-forces and competing between themselves for trading volume. If impediments to arbitrage become less binding, then market 
connectedness, integration and contagion will tend to increase as the market matures. Several studies directly or indirectly address these issues.

Ciaian et al. (2018), Corbet et al. (2018), and Phillips and Gorse (2018) find that cryptocurrencies are interconnected, especially in the short-term, but that the linkages are likely to be changing over time. Omane-Adjepong and Alagidede (2019) also show that the level of connectedness and volatility causal linkages of seven leading cryptocurrencies are time-varying, but, differently to previous studies, the authors also show that interdependence is quite weak in a daily horizon and increases with the trading scales. Koutmos (2018b) concludes that return and volatility spillovers among 18 cryptocurrencies have risen steadily over time, and, as in Katsiampa (2019b), documents that "spikes" in spillovers are observable during major news events regarding cryptocurrencies. Yi et al. (2018) show that all the 52 cryptocurrencies in the sample are strongly interconnected and that the connectedness between the major 8 cryptocurrencies has fluctuated cyclically, increasing when the market is experiencing unstable economic conditions or unpredictable exogenous shocks. Ferreira and Pereira (2019) find that the 10 top-capitalization cryptocurrencies (excepting Tether) exhibited an increased correlation with Bitcoin, especially after the end of 2017. The evidence supporting the interdependencies between cryptocurrencies is also found in other papers that look into the conditional covariance matrix derived from multivariate GARCH models and its variants (Aslanidis et al., 2019; Beneki et al., 2019; Cagli, 2019; Canh et al., 2019; Katsiampa, 2019a, 2019b; Katsiampa et al. , 2019a, 2019b; and Kumar and Anandarao, 2019). The main conclusion is that the cryptocurrencies' returns are mostly of the times positively correlated and that the interdependence changes over time and with market conditions, especially in different volatility regimes.

Some papers directly analyse the direction of the information flows between different cryptocurrencies, aiming to find out which is the leading one, but with mixed results. For example, Bação et al. (2018) investigate the information transmission between Bitcoin, Litecoin, Ripple, Ether, and Bitcoin Cash, concluding that most of the information transmission occurs within the day. However, some lagged information transmission occurs mainly from the other cryptocurrencies to Bitcoin, especially from Litecoin in the more recent period (August 4, 2017, to March 14, 2018). Koutmous (2018b) reports that Bitcoin is the dominant contributor of return and volatility spillovers, while Yi et al. (2018) conclude that Bitcoin is not the clear leader in terms of volatility spillovers, and some lowcapitalization cryptocurrencies are significant net-transmitters of volatility. Antonakakis et al. (2019) employ a time-varying parameter connectedness approach (a TVP-FAVAR model) to Bitcoin, Ethereum, Ripple, Dash, Litecoin, Monero, Nem, Stellar, and Bitshares, and find out that, although Bitcoin still influences the cryptocurrency market substantially, Ethereum has become the number one net transmitting cryptocurrency. Omane-Adjepong and Alagidede (2019) point out that cryptocurrencies with very large market capitalisation are more likely to transmit than to receive shocks from other cryptocurrencies; however, even the largest markets (Bitcoin and Ripple) are susceptible to receive volatility shocks from smaller markets. Ji et al. (2019a) examine connectedness via daily returns and volatility spillovers across Bitcoin, Ethereum, Ripple, Litecoin, Stellar and Dash, and show that Litecoin and Bitcoin are at the centre of returns and volatility connectedness. The authors show that Bitcoin is the most influential cryptocurrency in terms of volatility spillovers, while Ethereum is dominated by both larger and smaller cryptocurrencies. Zieba et al. (2019) compare interdependencies between the returns of cryptocurrencies, with a 
focus on Bitcoin in two sub-periods before and during the so-called ICO hype (December 2016). In the second sub-period, Bitcoin is not the most important cryptocurrency; at least it is not as important as it had been in the first sub-period. The results suggest that changes in the Bitcoin price do not affect and are not affected by changes in the price of the other cryptocurrencies and that Litecoin and Dogecoin are the most influential cryptocurrencies.

Some papers focus on the interdependence between cryptocurrencies during periods of extreme price movements and fast markets. Fry and Cheah (2016) provide some evidence that during the crash at the end of 2014, there was a spillover from Ripple that exacerbated the subsequent fall in Bitcoin. Zhang et al. (2019) find a strong correlation and tail dependence in the Bitcoin-Ethereum pair. Tiwari et al. (2019) show the existence of heavy tail dependence between each pair of cryptocurrencies (in the set formed by Bitcoin, Litecoin, and Ripple), particularly in the upper tail, and that the contagion effect runs mainly from Bitcoin to the other cryptocurrencies. Bouri et al. (2019c) show that the occurrence of periods of explosive price behaviour has increased and that these were especially frequent in 2017. Bitcoin is found to be the cryptocurrency that is most subject to long-lived explosive behaviour, and to be the least one affected by the "explosivity" of other cryptocurrencies. Nevertheless, Bouri et al. (2019c) conclude that there is a multidirectional "co-explosivity" that is not necessarily from bigger to smaller (and younger) cryptocurrencies.

Overall, these studies highlight the existence of strong interdependencies and connectedness between cryptocurrencies, most of the times showing positive conditional correlations with a long-run tendency to increase, significant asymmetric effects of positive and negative shocks, and tail dependence. These features have a markedly time-varying nature, depending on the market conditions such as price trends, volatility levels, and event news. These findings imply that cryptocurrencies are becoming more integrated, which leads to a higher degree of contagion risk. However, there is no consensus on whether Bitcoin is the dominant cryptocurrency in terms of information transmission, contagion, and volatility spillovers, or even whether cryptocurrencies with higher market capitalization dominate the other ones. So, it seems that results are highly dependent on the cryptocurrencies set and the sample period.

\section{Future challenges and perspectives}

4.1 The intensive energy consumption of the Proof-of-Work consensus protocol Probably the most important negative externality of cryptocurrencies, especially Bitcoin, is the alleged huge amount of electric energy needed to run the 'proof-of-work' (PoW) algorithm used in the mining activity. Different methodologies have been used to estimate the consumption of energy by cryptocurrencies resulting in quite different figures (see Kolbie, 2017), which has led to a heated debate on how much energy is really used. Nevertheless, since the early days of Bitcoin, some authors have addressed the issue of energy consumption (de Vries, 2018).

O'Dwyer and Malone (2014) estimate that, at the time of the study, the power used for Bitcoin mining was comparable to Ireland's electricity consumption. Küfeoğlu and Özkuran (2019) state that the historical peak of power consumption of Bitcoin mining took place during the fortnight commencing on December 18, 2017, with a demand between 1.3 and $14.8 \mathrm{GW}$. The maximum demand figure lies between the installed capacities of 
Denmark and Finland. The computing power required to solve one Bitcoin trade in 2019 has quadrupled compared to the previous year (Corbet et al., 2019). The Bitcoin Energy Consumption Index (which uses the portion of mining revenues being spent on electricity costs for its estimation), published in the Digiconomist platform (https://digiconomist.net/), achieved the value of 73.12 TWh in the second semester of 2019 , which is comparable to the power consumption of Austria. This index has been subjected to the criticism that it overestimates the energy consumption by Bitcoin; however, even the factual minimum estimate, computed as the product of network hash rate and energy efficiency of the most efficient miner, results in minimum annual electricity of Bitcoin mining to be $23.38 \mathrm{TWh}$ (Li et al., 2019). The scenario is even grimmer if other cryptocurrencies, that use a PoW consensus protocol, such as Ethereum, Bitcoin Cash, Litecoin, Monero, and ZCash, are included in these calculations.

Associated with the intensive consumption of electricity comes the problem of $\mathrm{CO} 2$ emissions. In December 2019, the carbon footprint per Bitcoin transaction was $310.33 \mathrm{~kg}$, i.e. $34.73 \mathrm{Mt}$ per annum - the equivalent to the total carbon emission of Denmark (Digiconomist, accessed 06 January 2020). Most mining pools, i.e. groups of miners working in specialised warehouses with extensive amounts of mining hardware, are situated in China, where most electricity production comes from coal-fired power plants (Rauchs et al., 2018; Corbet et al., 2019). Mora et al. (2018) project that Bitcoin alone could emanate enough $\mathrm{CO} 2$ to push global warming above $2{ }^{\circ} \mathrm{C}$ within less than three decades. Additionally, mining activity generates significant quantities of electronic waste (e-waste). Bitcoin mining is done with specialized (single purpose) hardware, which becomes obsolete roughly every 1.5 years (de Vries, 2019). Nowadays, Bitcoin mining generates around $10.12 \mathrm{kt}$ of e-waste, the equivalent to the country of Luxembourg (Digiconomist, accessed 06 January 2020). Collaterally, the amounts of energy required for mining cryptocurrencies puts pressure on the installed capacities for electric production and impacts on energy, commodity, technology and utility markets (Ji et al., 2019b; Symitsi and Chalvatzis, 2018; Corbet et al., 2019b) and even have a broad spectrum of consequences on the communities where the mining facilities are installed (Greenberg and Bugden, 2019).

We are at a point when governments and people worldwide are getting more and more concerned about pollution, environmental issues, and climate changes. When no one can be indifferent to the fact that humankind is probably facing the most important survival challenge in all its history, this status quo is hardly defensible. The mining community is aware of the negative environmental externalities of PoW algorithm, but most miners (especially the big ones) do not see the need to switch to another consensus algorithm in the future to address environmental concerns (Hileman and Rauchs, 2017; Rauchs et al. 2018). In other cases, the transition to more sustainable consensus protocols is being considered (e.g. in Ethereum) or has been successfully applied in other electronic currencies such as EOS.IO, which is in the 7 th place of the cryptocurrencies ranking according to market capitalization (CoinMarketCap, accessed on December 15, 2019). Zheng et al. (2017) propose various alternative consensus mechanisms, such as the Proofof-Stake (PoS), to address the energy consumption issue of PoW. On the other hand, many future blockchain applications tend to be based on the permissioned variant, where participants are identified, enabling the use of computationally lighter consensus algorithms. This reduces security, but improves efficiency and latency, and hence energy consumption is barely an issue (Vranken, 2017). 
Governments may help speed up the transition to more sustainable technologies. Truby (2018) discusses government intervention choices to dissocialize negative environmental externalities caused by high-energy consuming blockchain technology designs. For instance, fiscal policy tools can be applied to internalize negative externalities, and other government stimuli can be used to encourage a shift to less energy-intensive technologies without damaging the sector and put at risk the significant financial and economic benefits of blockchain.

\subsection{Blockchain everywhere?}

The blockchain characteristics that enabled cryptocurrencies have drawn attention for several other applications, financial and otherwise. In fact, the technology can be used in decentralized multi-participant situations where there is a need for trusted record-keeping without involving a central authority; when a shared control over the system is desirable; or when there is a need to know the provenance of goods and their full transactional history or to maintain the scarcity and uniqueness of a digital asset (Yaga et al., 2019).

Table 2 presents a non-exhaustive list of emerging applications of blockchain technology. Particularly notable is the potential for the advancement of developing economies (Kshetri, 2017; Cunha et al. 2020).

Table 3 Applications of blockchain technology

\begin{tabular}{|c|c|}
\hline Description & References \\
\hline $\begin{array}{l}\text { Supply chain operation } \\
\text { (e.g., in logistics, anti- } \\
\text { counterfeiting, finance, } \\
\text { transparency, safety) }\end{array}$ & $\begin{array}{l}\text { Maersk, IBM to launch blockchain-based platform for global trade: } \\
\text { https://www.reuters.com/article/us-maersk-blockchain-ibm/maersk-ibm-to-launch- } \\
\text { blockchain-based-platform-for-global-trade-idUSKBN1F51DE } \\
\text { The End-To-End Logistics Platform of The Future: Trustless, Transparent Tracking: } \\
\text { https://shipchain.io } \\
\text { Blockchain Based Anti-Counterfeit Solution: http://blockverify.io } \\
\text { Skuchain Developing Blockchain Solutions for } \$ 18 \text { Trillion Trade Finance Market With } \\
\text { Funding From Amino, DCG, and FBS Capital: https://www.prnewswire.com/news- } \\
\text { releases/skuchain-developing-blockchain-solutions-for-18-trillion-trade-finance-market- } \\
\text { with-funding-from-amino-dcg-and-fbs-capital-300214205.html } \\
\text { How Walmart brought unprecedented transparency to the food supply chain with } \\
\text { Hyperledger Fabric: https://www.hyperledger.org/resources/publications/walmart-case- } \\
\text { study } \\
\text { IBM Food Trust. A new era for the world's food supply: } \\
\text { https://www.ibm.com/blockchain/solutions/food-trust }\end{array}$ \\
\hline $\begin{array}{l}\text { Fraud reduction (e.g., } \\
\text { tax evasion, document } \\
\text { forgery avoidance) }\end{array}$ & $\begin{array}{l}\text { Fighting Tax Evasion with Blockchain - One Chinese City Leads the Fight: } \\
\text { https://toshitimes.com/fighting-tax-evasion-with-blockchain-one-chinese-city-leads-the- } \\
\text { fight/ } \\
\text { Thailand's Tax Authority Taps Blockchain to Fight Tax Evasion: } \\
\text { https://www.ccn.com/thailands-tax-authority-taps-blockchain-to-fight-tax-evasion/ } \\
\text { First Blockchain-Powered Government to Launch in Odessa, Ukraine: } \\
\text { https://cointelegraph.com/news/first-blockchain-powered-government-to-launch-in- } \\
\text { odessa-ukraine }\end{array}$ \\
\hline
\end{tabular}




\begin{tabular}{|c|c|}
\hline $\begin{array}{l}\text { Public registries and } \\
\text { notarization }\end{array}$ & $\begin{array}{l}\text { Using blockchain to make land registry more reliable in India: } \\
\text { http://www.undp.org/content/undp/en/home/blog/2018/Using-blockchain-to-make-land- } \\
\text { registry-more-reliable-in-India.html } \\
\text { Bitland Partners with CCEDK to Improve Blockchain Land Registry in West Africa: } \\
\text { http://www.econotimes.com/Bitland-partners-with-CCEDK-to-improve-blockchain-land- } \\
\text { registryin-West-Africa-271517 } \\
\text { Bitcoin.com Notary: https://notary.bitcoin.com }\end{array}$ \\
\hline $\begin{array}{l}\text { Intellectual property } \\
\text { protection }\end{array}$ & $\begin{array}{l}\text { Can Blockchain Technology Disrupt the Music Industry? } \\
\text { https://medium.com/blockstreethq/to-which-extent-can-blockchain-technology-disrupt- } \\
\text { the-music-industry-e6182fb5741a }\end{array}$ \\
\hline Insurance & $\begin{array}{l}\text { Blockchain in Insurance. Why should you care? } \\
\text { https://www2.deloitte.com/ca/en/pages/financial-services/articles/blockchain-in- } \\
\text { insurance.html } \\
\text { McKinsey Report Weighs Blockchain Impact on Insurance Industry: } \\
\text { http://www.coindesk.com/mckinsey-report-blockchain-insurance-impact/ }\end{array}$ \\
\hline E-commerce & $\begin{array}{l}\text { A Free Online Marketplace. No Platform Fees. No Restrictions. Earn Cryptocurrency: } \\
\text { https://openbazaar.org }\end{array}$ \\
\hline $\begin{array}{l}\text { Healthcare (e.g., in } \\
\text { managing medical } \\
\text { records and clinical } \\
\text { trial data) }\end{array}$ & $\begin{array}{l}\text { Blockchain: Opportunities for health care: } \mathrm{https} / / \mathrm{www} 2 . \text { deloitte.com/us/en/pages/public- } \\
\text { sector/articles/blockchain-opportunities-for-health-care.html } \\
\text { Blockchain in healthcare: https://www.ibm.com/blogs/blockchain/category/blockchain-in- } \\
\text { healthcare/ }\end{array}$ \\
\hline Digital identity & $\begin{array}{l}\text { Blockchain for Digital Identity: The Decentralized and Self-Sovereign Identity (SSI): } \\
\text { https://101blockchains.com/digital-identity/ } \\
\text { Digital Identity: https://www.r3.com/customers/digital-identity/ } \\
\text { IBM Verify Credentials: transforming digital identity into decentralized identity: } \\
\text { https://www.ibm.com/blockchain/solutions/identity }\end{array}$ \\
\hline Voting systems & $\begin{array}{l}\text { What if blockchain technology revolutionised voting? } \\
\text { https://www.europarl.europa.eu/RegData/etudes/ATAG/2016/581918/EPRS_ATA(2016) } \\
\text { 581918_EN.pdf } \\
\text { Can blockchain save the vote? https://techcrunch.com/sponsor/unlisted/can-blockchain- } \\
\text { save-the-vote/ } \\
\text { Could blockchain be the missing link in electronic voting? } \\
\text { https://www.zdnet.com/article/could-blockchain-be-the-missing-link-in-electronic-voting/ }\end{array}$ \\
\hline Banking and finance & $\begin{array}{l}\text { How Blockchain Technology Can Revolutionize Banking: https://www.accenture.com/cr- } \\
\text { en/insight-blockchain-technology-how-banks-building-real-time } \\
\text { Blockchain and retail banking: Making the connection: } \\
\text { https://www.mckinsey.com/industries/financial-services/our-insights/blockchain-and- } \\
\text { retail-banking-making-the-connection } \\
\text { How Blockchain Technology Will Impact the Banking Industry: } \\
\text { https://www.binance.vision/blockchain/how-blockchain-technology-will-impact-the- } \\
\text { banking-industry }\end{array}$ \\
\hline $\begin{array}{l}\text { Developing countries } \\
\text { (e.g., microfinancing, } \\
\text { faster and cheaper } \\
\text { remittances, donations } \\
\text { and aid tracking) }\end{array}$ & $\begin{array}{l}\text { China's Social Security to Use Blockchain Tech: } \\
\text { https://www.cryptocoinsnews.com/chinas-social-security-use-blockchain-tech/ } \\
5 \text { African crowdfunding startups to watch: https://disrupt-africa.com/2015/11/5-african- } \\
\text { crowdfunding-startups-to-watch/ } \\
\text { Bitcoin transactions cut the cost of international money transfers: } \\
\text { https://www.scmp.com/lifestyle/technology/article/1679904/bitcoin-transactions-cut-cost- } \\
\text { international-money-transfers } \\
\text { African Bitcoin Startup Wins Bill \& Melinda Gates Foundation Grant, Launches } \\
\text { Blockchain Event Series in Nairobi: https://bitcoinmagazine.com/articles/african-bitcoin- }\end{array}$ \\
\hline
\end{tabular}




\begin{tabular}{|l|l|}
\hline $\begin{array}{l}\text { startup-wins-bill-melinda-gates-foundation-grant-launches-blockchain-event-series- } \\
\text { nairobi-1436993383 } \\
\text { Banking the Unbanked: Mapping the Biggest Blockchain Projects in the Developing } \\
\text { World } \\
\text { https://blockexplorer.com/news/banking-the-unbanked-bitcoin-blockchain-projects- }\end{array}$ \\
$\underline{\text { developing-world/ }}$ \\
\hline
\end{tabular}

In some areas, such as commerce and banking, Blockchain may have profound implications. Arguably, in commerce, decentralized and peer-to-peer marketplaces will challenge traditional firm-controlled ones. LaZooz (http://lazooz.org), a ride-sharing network, and OpenBazaar (https://openbazaar.org) are examples of such decentralized marketplaces (Subramanian, 2017). The disintermediation of the transactions of products and services, as well as of payments (using digital currencies), will remove the need for trusted third parties (e.g., retailers and payment processors) and inhibit the creation of the current extensive databases of customer profiles. This will lead to increased anonymity, privacy, and efficiency (e.g., related to multi-party transaction costs). New stakeholders are also emerging: independent reputation brokers securely maintain buyer and seller reputations (Dennis and Owen, 2015; Migliardi et al. 2015), while blockchain-based digital identity services confirm user identities to commerce sites taking advantage of the cryptocurrencies wallet address, speeding up access while improving anonymity, security, and facilitating commerce since those wallets are already "enabled for purchase." (Swan, 2015). Ryan (2017) goes so far as to argue that “(...) blockchain's trust and reputation protocols have restored to online business some of the features of social contracting that were lost with the advent of the Internet. Blockchain-enabled smart contracts bring more certainty and reliability to online transactions than has been available to e-commerce environments for the past twenty years." Additionally, blockchain may help implementing collaborative circular economy business models, which in turn will create new wholesale and retail e-commerce markets (Alexandris et al., 2018; Casado-Vara et al., 2018).

Impacts of blockchain on banking exist at various levels. On the one hand, cryptocurrencies threat some banking staples, but, on the other hand, the technology has shown promise in addressing other challenges. The volume of worldwide cashless payments has increased significantly in recent years, especially in emerging markets (e.g., in China and India it increased more than five-fold over 2014 to 2018, and in Russia it has tripled). Card and e-money payments grew more rapidly than other noncash payments (Chang and Harano, 2020), raising the opportunity to use more regulated cryptocurrencies. JPMorgan appears to be considering issuing a digital currency called JPMorgan Coin to make instantaneous payments. It will be supported on a blockchain called Quorum, developed under the initiative of the bank. ${ }^{1}$ This same platform is already used by JPMorgan to run the Interbank Information Network, a payments network that involves more than 300 banks (Irrera, 2020). In some cases, blockchain has “(...) demonstrated its potential to materially reduce inventory lead times and lower operational costs, especially through the use of smart contracts" (Chang and Harano, 2020). It has also been used in matters related to security, namely Know Your Customer (KYC), using secure digital IDs, and in fighting multiple-invoice fraud (Chanjaroen and Boey, 2016). Laboure and Reid (2020a) argue that Fintech companies and smartphones have facilitated banking innovations, which will render plastic cards obsolete. But these innovations have also

\footnotetext{
${ }^{1}$ https://www.jpmorgan.com/country/UK/EN/Quorum\#section_1320553510217.
} 
created the grounds for a new integrated and dematerialised ecosystem for payments. Nowadays, bank back-office operations are highly concentrated on a few organisations that gather sensitive data and process billions of transactions in the world, with just a few points of vulnerability. According to the authors, there is a potential for significant efficiency gains in sharing and exchanging data in these back-office operations, which may be pursued using blockchain without put into question the security of the system.

This discussion of blockchain would not be complete without a word of warning. The enthusiasm surrounding this emergent technology sometimes leads to hasty adoption, based on misconceptions and without a complete understanding of its limitations (Yaga et al., 2019). As mere examples, note that the immutability of the ledger only holds if an attacker cannot dominate more than $50 \%$ of the network nodes; interactions with the physical world need to be carefully designed to prevent false data entering the blockchain; erroneous behaviour can be caused by bugs in the blockchain software or in the code of the smart contracts; and appropriate governance mechanisms must be set up for permissioned blockchains.

\subsection{Towards a cashless economy: Central bank digital currencies (CBDC)}

The increasing awareness of central banks of the disruptive and pervasive nature of blockchain, digital ledger technologies, and cryptocurrencies, has led them to seriously consider their features in national and cross-border wholesale and retail payment systems, and in the issuance and management of central bank currencies. Barontini and Holden (2019) report that all the 63 central banks surveyed, covering around $80 \%$ of the world population and $90 \%$ of the world economic output, were collaboratively looking at the implications of a central bank digital currency (CBDC), half of these central banks have already moved on to experiments and proof-of-concept activities to test these new technologies, and a quarter of them have, or will soon have, authority to issue a CBDC.

Wholesale and retail payment systems are already digital and, conceptually, blockchain technology may be used in both segments with significant efficiency, resiliency, and contingency improvements, especially in the wholesale segment where the digital platforms are ending their technological life cycles (Bech and Garratt, 2017). For instance, the Project Jasper at the Bank of Canada (Chapman et al., 2017) and the Project Ubin at the Monetary Authority of Singapore (Monetary Authority of Singapore, 2017) are amongst the earliest projects for the wholesale segment. These projects simulate real-time gross settlement systems (RTGS) on a digital ledger platform, where payments are processed individually, immediately, and with finality throughout the day. Conceivably, because these payment systems are backed up by central bank money, in the form of deposits, for purposes of clearing and settlement, they can be run through the use of a token on the distributed ledger that represents and is redeemable for central bank money. Given their nature, these systems should be permissioned, for identified participants who must be granted access.

However, CBDC usually refers not to a digital settlement token for wholesale payment applications (wholesale CBCD) but instead to an electronic form of central bank money that can be exchanged peer-to-peer (retail CBCD), or as Bech and Garratt (2017) put it, as a "widely available, consumer-facing payment instrument targeted at retail transactions", retaining the anonymity and universal acceptability features of cash (Bech and Garratt, 2017; Bjerg, 2017). It is this last concept of CBCD that we will discuss hereafter. 
In some cases, the eventual introduction of a CBDC is more of a reactive than a proactive measure. Although the demand for cash has risen in most advanced economies since the start of the last worldwide financial crisis, which, according to Bech et al. (2018), appears to be driven by store-of-value motives rather than by payment needs, some countries are experiencing the inverse trend. This is particularly true in the case of Sweden, where the payment market is going through a phase of significant change, driven by new digital technologies which have halved the amount of cash in circulation since 2007 (Sveriges Riksbank, 2019). This has been, for some time, a major cause for concern for the Sveriges Riksbank, the central bank of Sweden, due to the potential risks of financial instability and the deterioration of access to the payment services by certain groups of the population, namely the elderly. In March 2017, the Sveriges Riksbank launched the e-krona project, aiming at creating a digital complement to cash guaranteed by the state. The ekrona project is a landmark in the subject of CBDC, not only because of its degree of thoroughness but mostly because of its transparency, visible in the detailed reports produced recently (Sveriges Riksbank, 2017, 2018).

Naturally, the central bank retains the monopolistic right to issue the CBDC, and hence the possibility to stabilize its value, but, once issued, its circulation amongst users (banks, other financial and non-financial firms, and, most importantly, individual costumers) does not need active management from the central bank. At first glance, the implementation of CBDC just means the digitalization of cash and hence a new step, the last one, in the money dematerialization trend that has begun several centuries ago, but, in fact, it will have profound and structural implications.

Most central banks claim that the introduction of a CBDC may have positive effects in the payment system, which will spill over to the overall economy. This claim is present in several papers, such as Barrdear and Kumhof (2016) and Davoodalhosseini (2018), that conclude that the introduction of CBDC may have a positive macroeconomic affect. First, the implementation of a CBDC may increase the speed and reduce the costs of the payment systems, namely by reducing the frictions and costs associated with the storage, transport, and management of cash. Second, it has the potential to increase the resilience of the payment system to operational risks related to cyberattacks, operational failures, and hardware faults, and may reduce tax evasion, corruption, and illicit activities. Third, it may increase financial stability, by offering to retail depositors a default risk-free venue alternative to bank deposits and a lower risk alternative to private sector digital payment technologies, to counter operational risk or monopolistic control, especially in the situation of a structural decrease in cash usage. Fourth, it has the potential to increase the financial inclusion, especially in underbanked economies.

Conversely, the implementation of CBDC may exacerbate some of the existing risks and create new and unknown ones. Central banks may compete with the private banking sector for deposits, hence increasing the probability of severe financial instability episodes. Banks might be disintermediated and consequently be less able to perform essential economic functions, such as monitoring borrowers (Bech and Garratt, 2017). Also, bank runs might occur more frequently if the public is able to easily convert commercial bank money into risk-free central bank liabilities (Sveriges Riksbank, 2017). CBDC may raise consumer privacy and protection issues and may increase the financial exclusion of those groups that are already marginalized from the digital payment systems (WEF, 2019). Cyber-security risks and vulnerability and dependence on electricity are also important issues (Sveriges Riksbank, 2019). Additionally, there are some concerns that the blockchain technology is not yet properly developed to support CBDC, raising some issues 
on transaction scalability, user experience, key management, confidentiality, and transaction speeds.

In the last three years, the topic of CBDC has been under a hot and prolific debate involving central banks, academia, international organizations, and private entities. An important source of information is the online list, compiled by Lannquist (2020), and curated by the WEF, Centre for the Fourth Industrial Revolution, that contains more than 120 white papers, reports, and speeches related to the intersections of central banking, blockchain and distributed ledger technology, and CBDC (accessed on March 25, 2020). However, it seems that nowadays, central banks are valuing more the pros than the cons of using blockchain and issuing CBDCs, and probably that as to do with a more fundamental reason than those previously mentioned - the effectiveness of monetary policy.

Early central bank reports, such as Ali et al. (2014) and ECB (2015), pointed out that if Bitcoin becomes widely accepted as a medium of payment, then it would have the potential to undermine the effectiveness of monetary policy not only in terms of financial stability, as there are no automatic or supervised mechanisms to alleviate the impact of shocks, but also in terms of monetary stability, because the supply of Bitcoin is capped and hence it is intrinsically prone to deflationary processes. In an extreme scenario, the monetary authority may not only lose control over the money supply and credit, but also the ability to provide lender-of-last-resort support (Niepelt, 2016). Additionally, Pieters (2017) highlights that Bitcoin may create problems for those countries, such as Argentina, that have chosen in their external monetary policy toolkit to apply restrictions to international capital flows, simply because cryptocurrencies bypass those capital controls. Although, some authors still argue that cryptocurrencies do not pose a serious threat to monetary policy effectiveness (Nelson, 2018), central banks clearly state that CBDC is probably the best way to react to a non-trivial possibility that cryptocurrencies may undermine monetary policy effectiveness (Sveriges Riksbank, 2017, 2018, 2019; Barontini and Holden, 2019). CBCD will directly fulfil the need for digitalization, will narrow the relationship between citizens and central banks and remove the need for the public to keep deposits in fractional reserve commercial banks (Raskin and Yermack, 2018), collaterally it will impose a better discipline on commercial banks (Thakor, 2020), reduce the vulnerability of banks, and reduce the political and economic incentives to governments to bail out the "too big to fail" institutions (Niepelt, 2018).

Most importantly, account-based interest-bearing CBDC will also provide the central banks with an additional monetary policy tool, relieving the zero lower bound constraint on monetary policy and increasing the effectiveness of monetary policy in recessionary and deflationary periods (Bordo and Levin, 2017; Sveriges Riksbank, 2017, 2019; Barontini and Holden, 2019; WEF, 2019).

\section{Conclusion}

Cryptocurrencies have no legal tender and no intrinsic value. They may serve as a medium of exchange in certain restricted contexts, but they provide a very poor service as a unit of account and store of value, due to their hyper volatility and erratic price behaviour characterized by recurrent bubbles and jumps. As they stand today, cryptocurrencies can be considered a new kind of tradable speculative asset, with its acceptance deriving exclusively from the confidence of its users. For instance, Katz (2017) states that, at the end of 2016, only 5 of the top 500 online merchants accepted Bitcoin, with the number 
decreasing to 3 at the end of 2017, which highlights the speculative nature of cryptocurrencies. This evidence supports the viewpoint of earlier critics of Bitcoin that argued that this was only an instrument for high-stakes gambling (Glaser et al., 2014; Baeck and Elbeck, 2015).

The use of Bitcoin as a speculative asset instead of a medium of leads us to argue that the initial libertarian ideal that underlined the creation of Bitcoin has been subverted. The peer-to-peer interactions of Bitcoin and other cryptocurrencies are, nowadays, marginal, with most trades occurring through intermediaries - the online centralized exchanges (Rauchs et al., 2018). The increase in capital requirements and the reduction of rewards for the mining activity has created barriers to newcomers and caused the drop out of those miners that could not keep up, leading to an oligopolistic structure in the mining activity. In fact, the five largest miners, which are mostly based in China, mined over $85 \%$ of the blocks in 2016 (Vranken, 2017). Also, it seems that the Bitcoin market is far from being atomistic, as most existing Bitcoins are held by a handful of "whales" (i.e. big traders with wallets worth 1 billion USD or more). Moreover, the financial industry and, in particular, central banks, are adopting the concepts of cryptocurrency and blockchain, which is undoubtedly a twist to the principles subscribed by the libertarian ideology.

The impediments to the use of existing cryptocurrencies as a medium of payment may be resolved if stablecoins, issued by private or public entities, are implemented. These second-generation cryptocurrencies are designed to have low volatility as they may be pegged to fiat money, exchange-traded assets, or even other cryptocurrencies, and can be redeemable in that claim or can be seigniorage if the price is guaranteed by an algorithm. Facebook's Libra project intended to create such a stablecoin, however, it seems that it has not yet been implemented due to intense regulatory pressure given the associated systemic risks. Nevertheless, this project puts into perspective the feasibility of a cryptocurrency mainly designed to serve a medium of payment, which will surely have a wide acceptance if supported by the state (Bullmann et al., 2019).

Bitcoin and other cryptocurrencies have been subjected to several reputational drawbacks. There are well-founded suspicions that online exchanges, especially the Asian ones, have been reporting fictitious high trading volumes to attract new clients (Sebastião et al., 2017). There are frequent claims of price manipulation occurrences, namely through Pump-and-Dump scams (Gandal et al., 2018; Kamps and Kleinberg, 2018), and also that cryptocurrencies have been widely used as a vehicle for money laundry (Wegberg et al., 2018), tax evasion (Marian, 2013), and financing terrorism (Teichmann, 2018). Additionally, the history of cryptocurrencies is teeming with episodes of online exchange hackings, thefts of cryptocurrencies wallets, fake cryptocurrencies and online exchanges, and lawsuits resulting from their use as a medium of payment for drugs and other illegal activities in the dark web (e.g. the arrest and trial of Ross Ulbricht in the Silk Road process, Higgins, 2017). In fact, according to some researchers, one of the main driving forces for trading Bitcoin is its use in financing illegal activities. For instance, Foley et al. (2019) argue that around one-quarter of Bitcoin users and one-half of Bitcoin transactions are associated with illegal activities, involving about 72 billion USD per year, an amount close to the scale of the US and European markets for illegal drugs. All these malpractices have been flourishing in a regulatory void, or in the words of Corbet et al. (2019c), in the presence of clear regulatory disorientation. Conceptually, cryptocurrencies have their merits (e.g. cost-efficiency, accessibility, portability, transparency, integrity, and resilience), and, as such, should not be simply banned. Also, although the market has been expanding in terms of the number of existing cryptocurrencies, online exchanges, and 
trading volume, the former two will eventually decrease in the near future, due to the increased competition. Arguably, this restructuring of the cryptocurrencies landscape will also be influenced by public opinion, due to the increasing concerns with environmental issues, which may disincentive cryptocurrencies that make use of an intensive consumption of energy, such as Bitcoin and Ethereum. Ultimately, a new regulatory framework, concerted at the worldwide scale, aimed at inhibiting malpractices and stimulating the shift to less energy-intensive technologies, must be a priority item in the agenda of regulators and policymakers. This task will be simplified as less and less trading is conducted in a peer-to-peer manner, but rather through centralized exchanges that dominate the market.

In recent years, the initial reluctance of central banks towards cryptocurrencies and blockchain also faded away, as these institutions, in both developed and developing countries, are seriously considering the implementation of blockchain in national and cross-border wholesale and retail payment systems, and in the issuance and management of central bank digital currencies (CBDC). Efficiency and safety of the national and crossborder payment system, financial stability, financial inclusion, and monetary policy implementations are amongst the reasons advocated by central banks to pursue this avenue. This is especially attractive in countries, such as Sweden, where the usage of cash is dropping significantly. With CBDC, central banks will retain the issuance monopoly, but currency circulation among users will be conducted through a distributed ledger. The implementation of CBDC not only means the digitalization of the existing fiat money but also will have other structural implications, namely on the way that central banks conduct the monetary policy. This trend will be fostered, and reversely will foster, the new habits of payment, that have recently been building up based on the availability of new, faster and cheaper electronic payment services, new consumption patterns, and supply channels such based on e-commerce. The intensive consumption of energy will not be an issue in this case because the CBDC will be based on permissioned digital ledgers. However, there will be new risks in terms of financial stability, financial inclusion, consumer privacy and protection, and other operational risks related to the resilience of the blockchain technologies to cyber-attacks and to their vulnerability to power outages (Sveriges Riksbank, 2019; WEF, 2019). In making a decision towards CBDC, central banks will have to consider not only consumer preferences for privacy and possible efficiency gains in terms of payments, clearing and settlement, but also the risks it may entail for the financial system and the broader economy, which are, to a great extent, still unmeasurable.

CBDC may be an economical and geopolitical "game-changer". A state could use a CBCD outside the traditional payment systems to compete with reserve currencies in a region, to potentially increase its economic influence and political power, bypass international regulations or sanctions, or strengthen autocratic regimes, as it seems to be the cases of Iran and Venezuela (WEF, 2019). CBCD may be used in an overall strategic plan to prepare countries for war, as the central bank of Sweden clearly states: "Due to the deteriorated security policy situation in Europe, the Government has decided to resume Sweden's total defence. (...) The Riksbank's position is that several prerequisites must be met in order for payments to function during a heightened state of alert. Among these, there should be a variety of alternative means of payment and a robust supply of electricity and electronic communications." (Sveriges Riksbank, 2019, pp. 38-39).

Ultimately, CBCD may disrupt the existing global economic order. Since the end of 2018, the Internet has been teeming with rumours that the People's Bank of China was secretly preparing the implementation of its own cryptocurrency (see, for instance, Murphy and Yang, 2020; Xuanmin, 2020). It wasn't with great surprise that in April 2020, the world 
received the news that China was going to introduce a digital renminbi (e-RMB) in the payment systems of three cities (Shenzhen, Suzhou and Chengdu) that have more than 38 million inhabitants, and also in Xiong'na, which was established in 2017 under the direct control of the Central Committee of the Chinese Communist Party aiming to be an administrative and economic hub. Arguably the People's Bank of China may efficiently use this digital currency within the One Belt One Road initiative. If so, this will allow China to control emerging markets where most of the economic growth will take place in the coming decades, give China new ammunitions to fight the trade war initiated by the current US administration, and ultimately jeopardize the international hegemony of USD (Scott, 2018; Laboure and Reid, 2020b).

Since the original whitepaper introducing Bitcoin (Nakamoto, 2008), blockchain technology has garnered significant attention, far beyond the realm of cryptocurrencies. Arguably, it can be used in any multi-participant environment that requires trusted transactions without employing a third trusted party. Many applications of blockchain, financial or otherwise, have been proposed or are already in place, from which the potential for the advancement of developing economies stands out. For the WEF (2015), this technology is one of the megatrends that will shape the world in the next decade, and some authors even argue that the blockchain technology is an innovation only comparable to the introduction of the World Wide Web. Definitively, in our understanding, the blockchain is here to stay, and most probably cryptocurrencies, as they exist today, are the poorest example on how to use it.

At the time of writing, humankind is living real stressful times due to the Covid-19 pandemic surge. People are confined to their homes, inhibited of social interaction. Most firms are pursuing labour layout schemes, unemployment is growing rapidly, and supply chains are breaking worldwide. By now, we are experiencing an economic destruction unprecedented in modern times, which will take some time to be fully revealed and many more years to resolve. When the traditional financial markets were crashing worldwide, the cryptocurrencies also fell. In just 24 hours, on March 12, 2020, the Bitcoin price index published by the CoinMarketCap site, dropped from $\$ 7^{\prime} 913$ to $\$ 4^{\prime} 971$ - a daily rate of return of around $-37.2 \%$. Once again, cryptocurrencies failed the real stress test. Bitcoin and other cryptocurrencies did not provide the hedging, diversification and safe-haven services highlighted by some authors (Colon and McGee, 2020).

The pandemic crisis created an urge for digitalization, not only in the many aspects of the daily life of families but also in the way firms conduct their businesses and states govern national affairs. We believe that this ongoing scenario will reinforce what has been discussed previously. Private cryptocurrencies will be subjected to a fierce restructuration in the near future, the implementations of blockchain will spread out at a visible rate as long as funds remain available for digital innovation, the system of payments will be subjected to other forms of digitalization and central banks will speed up the adoption of account-based interest-bearing CBDC, especially if it can be used through smartphones and personal computers. Even if cash does not entirely disappear, a society where it is no longer the unique generally accepted medium of payment supported by the state will most probably emerge in just a fewer years' time. 


\section{References}

Aalborg, H. A., Molnár, P. and de Vries, J. E. (2019) 'What can explain the price, volatility and trading volume of Bitcoin?', Finance Research Letters, Vol. 29, pp.255-265.

Abraham, L. and Guegan, D. (2019) 'The other side of the coin: Risks of the Libra blockchain', University Ca' Foscari of Venice, Dept. of Economics Research Paper Series, No. 30/WP/2019. https://ssrn.com/abstract=3474237 (Accessed 14 April 2020).

Akyildirim, E., Corbet, S., Katsiampa, P., Kellard, N. and Sensoy, A. (2019) 'The development of Bitcoin futures: Exploring the interactions between cryptocurrency derivatives', Finance Research Letters. https://doi.org/10.1016/j.frl.2019.07.007 (Accessed 14 April 2020).

Alessandretti, L., ElBahrawy, A., Aiello, L. M. and Baronchelli, A. (2018) 'Machine learning the cryptocurrency market', SSRN 23 May. https://ssrn.com/abstract=3183792 (Accessed 14 April 2020).

Alexander, C., Choi, J., Park, H. and Sohn, S. (2019) 'BitMEX bitcoin derivatives: Price discovery, informational efficiency, and hedging effectiveness', Journal of Futures Markets. https://doi.org/10.1002/fut.22050 (Accessed 14 April 2020).

Ali, R.; Barrdear, J.; Clews, R. and Southgate, J. (2014) 'The Economics of Digital Currencies', Quarterly Bulletin, Bank of England, Q3. https://ssrn.com/abstract=2499418 (Accessed 26 June 2010).

Ali, A., Latif, S., Qadir, J., Kanhere, S., Singh, J. and Crowcroft, J. (2019) 'Blockchain and the future of the Internet: A comprehensive review', arXiv preprint, arXiv:1904.00733.

Alexandris, G., Katos, V., Alexaki, S. and Hatzivasilis, G. (2018) 'Blockchains as enablers for auditing cooperative circular economy networks'. In 2018 IEEE 23rd International Workshop on Computer Aided Modeling and Design of Communication Links and Networks (CAMAD), IEEE, pp.1-7.

Antonakakis, N., Chatziantoniou, I. and Gabauer, D. (2019) 'Cryptocurrency market contagion: Market uncertainty, market complexity, and dynamic portfolios', Journal of International Financial Markets, Institutions and Money, Vol. 61, pp.37-51.

Aslanidis, N., Bariviera, A.F. and Martínez-Ibañez, O. (2019) 'An analysis of cryptocurrencies conditional cross correlations', Finance Research Letters, Vol. 31, pp.130-137.

Bação, P., Duarte, A.P., Sebastião, H. and Redzepagic S. (2018) 'Information transmission between cryptocurrencies: Does Bitcoin rule the cryptocurrency world?', Scientific Annals of Economics and Business, Vol. 65, No. 2, pp.97-117.

Baeck C. and Elbeck M. (2015) 'Bitcoins as an investment or speculative vehicle? A first look', Applied Economic Letters, Vol. 22, No 1, pp.30-34.

Balcilar, M., Bouri, E., Gupta, R. and Roubaud, D. (2017) 'Can volume predict Bitcoin returns and volatility? A quantiles-based approach', Economic Modelling, Vol. 64, pp.74-81. 
Barontini, C. and Holden, H. (2019) 'Proceeding with caution - a survey on central bank digital currency', BIS Paper, No. 101, January. https://www.bis.org/publ/bppdf/bispap101.pdf (Accessed 14 April 2020).

Bariviera, A.F. (2017) 'The inefficiency of Bitcoin revisited: A dynamic approach', Economics Letters, Vol. 161, pp.1-4.

Bariviera, A.F. and Merediz-Sola, I. (2020) 'Where do we stand in cryptocurrencies economic research? A survey based on hybrid analysis'. http://dx.doi.org/10.2139/ssrn.3553071 (Accessed 26 June 2020).

Barrdear, J. and Kumhof , M. (2016) 'The macroeconomics of central bank issued digital currencies', Bank of England, Staff Working Paper No. 605. http://dx.doi.org/10.2139/ssrn.2811208 (Accessed 26 June 2020).

Bartoletti, M. and Pompianu, L. (2017) 'An empirical analysis of smart contracts: platforms, applications, and design patterns'. In International conference on financial cryptography and data security, Springer, Cham, pp.494-509.

Baur, D. G., Dimpfl, T. and Kuck, K. (2018) 'Bitcoin, gold and the US dollar-A replication and extension', Finance Research Letters, Vol. 25, pp.103-110.

Baur, D.G. and Dimpfl, T. (2019) 'Price discovery in Bitcoin spot or futures?', Journal of Futures Markets. https://doi.org/10.1002/fut.22004 (Accessed 14 April 2020).

Baur, D.G., Hong, K. and Lee, A.D. (2018) 'Bitcoin: Medium of exchange or speculative assets?', Journal of International Financial Markets, Institutions \& Money, Vol. 54, pp.177-189.

Bech, M.L. and Garratt, R. (2017) 'Central bank cryptocurrencies', BIS Quarterly Review, September, pp.55-70. https://ssrn.com/abstract=3041906 (Accessed 20 June 2020).

Bech, M., Faruqui, U., Ougaard, F. and Picillo, C. (2018) 'Payments are a-changin' but cash still rules', BIS Quarterly Review, March, pp.67-80. https://ssrn.com/abstract=3139217 (Accessed 20 June 2020).

Beck, R., Müller-Bloch, and King, C.J.L. (2018) 'Governance in the blockchain economy: A framework and research agenda', Journal of the Association for Information Systems, Vol. 19, No. 5, pp.1020-1034.

Beneki, C., Koulis, A., Kyriazis, N.A. and Papadamou, S. (2019) 'Investigating volatility transmission and hedging properties between Bitcoin and Ethereum', Research in International Business and Finance, Vol. 48, pp.219-227.

Berkley, J. (2015) 'The promise of the blockchain. The trust machine', The Economist, Oct 31st 2015 edition. https://www.economist.com/leaders/2015/10/31/the-trust-machine (Accessed 22 June 2020).

Bjerg, O (2017) 'Designing new money - the policy trilemma of central bank digital currency', Copenhagen Business School (CBS) Working Paper, June. https://research.cbs.dk/en/publications/designing-new-money-the-policy-trilemma-ofcentral-bank-digital-c (Accessed 14 April 2020).

Blau, B.M. (2017) 'Price dynamics and speculative trading in Bitcoin', Research in International Business and Finance, Vol. 41, pp.493-499. 
Bordo, M. and Levin, A. (2017) 'Central bank digital currency and the future of monetary policy', NBER Working Papers, no 23711, August. http://www.nber.org/papers/w23711 (Accessed 02 January 2020).

Bouoiyour, J. and Selmi, R. (2014) 'What Bitcoin looks like?', MPRA Working Paper No. 58091, University Library of Munich, Germany. https://mpra.ub.unimuenchen.de/58091/ (Accessed 22 June 2020).

Bouri, E., Molnár, P., Azzi, G., Roubaud, D. and Hagfors, L.I. (2017) 'On the hedge and safe haven properties of Bitcoin: Is it really more than a diversifier?', Finance Research Letters, Vol. 20, pp.192-198.

Bouri, E., Gupta, R. and Roubaud, D. (2019a) 'Herding behaviour in cryptocurrencies', Finance Research Letters, Vol. 29, pp.216-221.

Bouri, E., Lau, C. K. M., Lucey, B. and Roubaud, D. (2019b) 'Trading volume and the predictability of return and volatility in the cryptocurrency market', Finance Research Letters, Vol. 29, pp.340-346.

Bouri, E., Shahzad, S.J.H. and Roubaud, D. (2019c) 'Co-explosivity in the cryptocurrency market', Finance Research Letters, Vol. 29, pp.178-183.

Brandvold, M., Molnár, P., Vagstad, K. and Valstad, O. C. A. (2015) 'Price discovery on Bitcoin exchanges', Journal of International Financial Markets, Institutions and Money, Vol. 36, pp.18-35.

Brauneis, A. and Mestel, R. (2018) 'Price discovery of cryptocurrencies: Bitcoin and beyond', Economics Letters, Vol. 165, pp.58-61.

Brühl, V. (2019) 'LIBRA - a differentiated view on Facebook's virtual currency project', CFS Working Paper Series, No. 633, Goethe University, Center for Financial Studies (CFS), Frankfurt https://www.econstor.eu/bitstream/10419/206412/1/1680695878.pdf (Accessed 14 April 2020).

Bullmann, D., Klemm, J. and Pinna, A. (2019) 'In search for stability in crypto-assets: Are stablecoins the solution?', ECB, Occasional Paper No. 230. https://papers.ssrn.com/sol3/papers.cfm?abstract_id=3444847. (Accessed 16 April 2020).

Cagli, E. C. (2019) 'Explosive behavior in the prices of Bitcoin and altcoins', Finance Research Letters, Vol. 29, pp.398-403.

Canh, N.P., Wongchoti, U., Thanh, S.D., Thong, N.T (2019) 'Systematic risk in cryptocurrency market: Evidence from DCC-MGARCH model', Finance Research Letters, Vol. 29, pp.90-100.

Caporale, G.M., Gil-Alana, L. and Plastun, A. (2018) 'Persistence in the cryptocurrency market', Research in International Business and Finance, Vol. 46, pp.141-148.

Casino, F., Dasaklis, T.K. and Patsakis, C. (2019) 'A systematic literature review of blockchain-based applications: current status, classification and open issues', Telematics and Informatics, Vol. 36, pp.55-81. 
Castor, A. (2014) 'A (short) guide to blockchain consensus protocols', CoinDesk. [online]. https://www.coindesk.com/short-guide-blockchain-consensus-protocols (Accessed 22 June 2020).

Casado-Vara, R., Prieto, J., De la Prieta, F., and Corchado, J.M. (2018) 'How blockchain improves the supply chain: Case study alimentary supply chain'. Procedia Computer Sscience, Vol. 134, pp.393-398.

Catania, L., Grassi, S. and Ravazzolo, F. (2019) 'Forecasting cryptocurrencies under model and parameter instability', International Journal of Forecasting, Vol. 35, No. 2, pp.485-501.

Chan, W. H., Le, M. and Wu, Y. W. (2019) 'Holding Bitcoin longer: The dynamic hedging abilities of Bitcoin', The Quarterly Review of Economics and Finance, Vol. 71, pp.107113.

Chang, J. and Harano, K. (2020) 'Blockchain, digital currency and cryptocurrency: Moving into the mainstream?', Global Research, February, J.P. Morgan Perspectives, 2020. [online]. https://markets.jpmorgan.com/research/ (Accessed 17 June 2020).

Chanjaroen, C. and Boey, D. (2016) 'Fraud in \$4 Trillion Trade Finance Has Banks Turning Digital', Bloomberg, May $22 . \quad$ [online]. https://www.bloomberg.com/news/articles/2016-05-22/fraud-in-4-trillion-tradefinance-turns-banks-to-digital-ledger (Accessed 17 June 2020).

Chapman, J., Garratt, R., Hendry, S., McCormack, A. and McMahon, W. (2017) 'Project Jasper: are distributed wholesale payment systems feasible yet?', Bank of Canada, Financial System Review, June, pp.1-11. https://www.bankofcanada.ca/wpcontent/uploads/2017/06/fsr-june2017.pdf (Accessed 17 June 2020).

Charfeddine, L. and Maouchi, Y. (2019) 'Are shocks on the returns and volatility of cryptocurrencies really persistent?', Finance Research Letters, Vol. 28, pp.423-430.

Cheah, E.-T. and Fry, J. (2015) 'Speculative bubbles in Bitcoin markets? An empirical investigation into the fundamental value of Bitcoin', Economics Letters, Vol. 130, pp.32-36.

Cheung, A., Roca, E. and Su, J.-J. (2015) 'Crypto-currency bubbles: An application of the Phillips-Shi-Yu (2013) methodology on Mt.Gox Bitcoin prices', Applied Economics, Vol. 47, No. 23, pp. 2348-2358.

Ciaian, P., Rajcaniova, M. and Kancs, d'A. (2016) 'The economics of Bitcoin price formation', Applied Economics, Vol. 48, No. 19, pp.1799-1815.

Ciaian, P., Rajcaniova, M. and Kancs, d'A. (2018) 'Virtual relationships: Short-and longrun evidence from Bitcoin and altcoin markets', Journal of International Financial Markets, Institutions and Money, Vol. 52, pp.173-195.

Conlon, T. and McGee, R. (2020) 'Safe haven or risky hazard? Bitcoin during the Covid19 bear market', SSRN, 24 March. https://ssrn.com/abstract=3560361 (Accessed 14 April 2020).

Corbet, S., Meegan, A., Larkin, C., Lucey, B. and Yarovaya, L. (2018) 'Exploring the dynamic relationships between cryptocurrencies and other financial assets', Economics Letters, Vol. 165, pp.28-34. 
Corbet, S., Eraslan, V., Lucey, B. and Sensoy, A. (2019a) 'The effectiveness of technical trading rules in cryptocurrency markets', Finance Research Letters, Vol. 31, pp.32-37.

Corbet, S., Lucey, B.M. and Yarovaya, L. (2019b) 'The financial market effects of cryptocurrency energy usage', SSRN, 29 June. https://ssrn.com/abstract=3412194 (Accessed 14 April 2020).

Corbet, S., Lucey, B., Urquhart, A. and \& Yarovaya, L. (2019c) 'Cryptocurrencies as a financial asset: A systematic analysis', International Review of Financial Analysis, Vol. 62, pp.182-199.

Cunha, P.R., Soja, P. and Themistocleous, M. (2020) 'Blockchain for development: preliminary insights from a literature review. In Americas Conference on Information Systems (AIS), Aug 10-14, Salt Lake City, Utah, USA.

Dasgupta, D., Shrein, J.M. and Gupta, K. D. (2019) 'A survey of blockchain from security perspective', Journal of Banking and Financial Technology, Vol. 3, No. 1, pp.1-17.

Dastgir, S., Demir, E., Downing, G., Gozgor, G. and Lau, C.K.M. (2019) 'The causal relationship between Bitcoin attention and Bitcoin returns: Evidence from the Copulabased Granger causality test', Finance Research Letters, Vol. 28, pp.160-164.

Davoodalhosseini, S.M.R. (2018) 'Central bank digital currency and monetary policy', Bank of Canada, Staff Working Paper 2018-36. http://dx.doi.org/10.2139/ssrn.3011401 (Accessed 25 June 2020).

de Souza, M.J.S., Almudhaf, F.W., Henrique, B.M., Negredo, A.B.S., Ramos, D.G.F., Sobreiro, V. A. and Kimura, H. (2019) 'Can Artificial Intelligence enhance the Bitcoin bonanza', The Journal of Finance and Data Science, Vol. 5, No. 2, pp.83-98.

de Vries, A. (2018) 'Bitcoin's growing energy problem', Joule, Vol. 2, No. 5, pp.801-805

de Vries, A. (2019) 'Renewable energy will not solve Bitcoin's sustainability problem', Joule, Vol. 3, No. 4, pp.893-898.

Dennis, R. and Owen, G. (2015) 'Rep on the block: A next generation reputation system based on the blockchain'. In 2015 10th International Conference for Internet Technology and Secured Transactions (ICITST), December, pp. 131-138. IEEE. https://doi.org/10.1109/ICITST.2015.7412073 (Accessed 14 December 2019).

Dwyer, G. P. (2015) 'The economics of Bitcoin and similar private digital currencies', Journal of Financial Stability, Vol. 17, pp.81-91.

Dyhrberg, A. H. (2016a) 'Bitcoin, gold and the dollar - A GARCH volatility analysis'. Finance Research Letters, Vol. 16, pp.85-92.

Dyhrberg, A. H. (2016b) 'Hedging capabilities of bitcoin. Is it the virtual gold?', Finance Research Letters, Vol. 16, pp.139-144.

ECB (2015) Virtual currency schemes - a further analysis, European Central Bank. https://www.ecb.europa.eu/pub/pdf/other/virtualcurrencyschemesen.pdf (Accessed 26 June 2010).

El Alaoui, M., Bouri, E. and Roubaud, D. (2018) 'Bitcoin price-volume: A multifractal cross-correlation approach', Finance Research Letters. https://doi.org/10.1016/j.frl.2018.12.011 (Accessed 14 April 2020). 
Ethereum (2019). What is Ethereum?. [online]. https://ethereum.org/beginners/ (Accessed 14 December 2019).

European Commission (2018) FinTech Action plan: For a more competitive and innovative European financial sector https://ec.europa.eu/info/sites/info/files/180308-actionplan-fintech_en.pdf (Accessed 14 April 2020)

Fang, L., Bouri, E., Gupta, R. and Roubaud, D. (2019) 'Does global economic uncertainty matter for the volatility and hedging effectiveness of Bitcoin?', International Review of Financial Analysis, Vol. 61, pp.29-36.

Ferreira, P. and Pereira, É. (2019) 'Contagion effect in cryptocurrency market', Journal of Risk and Financial Management, Vol. 12, No. 3, pp.115.

Foley, S., Karlsen, J.R., and Putniňš, T. J. (2019) 'Sex, drugs, and bitcoin: How much illegal activity is financed through cryptocurrencies?', The Review of Financial Studies, Vol. 32, No. 5, pp. 1798-1853.

Fry, J. and Cheah, E. T. (2016) 'Negative bubbles and shocks in cryptocurrency markets', International Review of Financial Analysis, Vol. 47, pp. 343-352.

Gandal, N., Hamrick, J. T., Moore, T. and Oberman, T. (2018) 'Price manipulation in the Bitcoin ecosystem', Journal of Monetary Economics, Vol. 95, pp. 86-96.

Gerritsen, D. F., Bouri, E., Ramezanifar, E. and Roubaud, D. (2019) 'The profitability of technical trading rules in the Bitcoin market', Finance Research Letters, https://doi.org/10.1016/j.frl.2019.08.011 (Accessed 14 April 2020).

Giudici, G., Milne, A. and Vinogradov, D. (2020) 'Cryptocurrencies: market analysis and perspectives', Journal of Industrial and Business Economics, Vol. 47, No. 1, pp.1-18.

Gkillas, K. and Katsiampa, P. (2018) 'An application of Extreme Value Theory to cryptocurrencies', Economics Letters, Vol. 164, pp.109-111.

Glaser, F., Zimmermann, K., Haferkorn, M., Weber, M.C. and Siering, M. (2014) 'Bitcoin - asset or currency? Revealing users' hidden intentions', in Twenty Second European Conference on Information Systems, Tel Aviv. https://papers.ssrn.com/sol3/papers.cfm?abstract_id=2425247 (Accessed 14 April 2020).

Greenberg, P. and D. Bugden (2019) 'Energy consumption boomtowns in the united states: Community responses to a cryptocurrency boom', Energy research Social Science, Vol. 50, pp.162-167.

Grobys, K. and Sapkota, N. (2019) 'Cryptocurrencies and momentum', Economics Letters, Vol. 180, pp.6-10.

Grobys, K., Ahmed, S. and Sapkota, N. (2019) 'Technical trading rules in the cryptocurrency market', Finance Research Letters, https://doi.org/10.1016/j.frl.2019.101396 (Accessed 14 April 2020).

Groß, J., Herz, B. and Schiller, J. (2019) 'Libra - Concept and policy implications', Wirtschaftswissenschaftliche Diskussionspapiere, No. 02-19, Universitat Bayreuth, Bayreuth. $\quad$ https://www.econstor.eu/bitstream/10419/205241/1/WP 02-19.pdf (Accessed 14 April 2020). 
Guesmi, K., Saadi, S., Abid, I. and Ftiti, Z. (2019) 'Portfolio diversification with virtual currency: Evidence from bitcoin', International Review of Financial Analysis, Vol. 63, pp.431-437.

Gupta, M. (2017) Blockchain for Dummies, IBM Limited Edition, John Wiley \& Sons.

Hale, G., Krishnamurthy, A., Kudlyak, M. and Shultz, P. (2018) 'How futures trading changed Bitcoin prices', FRBSF Economic Letter, Vol. 12, 7 May. https://www.frbsf.org/economic-research/publications/economicletter/2018/may/how-futures-trading-changed-bitcoin-prices/ (Accessed 14 April 2020).

Heath, A. (2020). 'Facebook revamps Libra plans, bowing to regulators', The Information. [online] https://www.theinformation.com/articles/facebook-scales-back-libra-plansbowing-to-regulators (Accessed 14 April 2020).

Higgins, S. (2017) 'Ross Ulbricht drops claim to millions raised in Silk Road Bitcoin Auctions', Coindesk. [online]. https://www.coindesk.com/ross-ulbricht-drops-claimmillions-raised-silk-road-bitcoin-auctions (Accessed 16 April 2020).

Hileman, G. and Rauchs, M. (2017) Global cryptocurrency benchmarking study, University of Cambridge, Cambridge Center for Alternative Finance. https://www.crowdfundinsider.com/wp-content/uploads/2017/04/GlobalCryptocurrency-Benchmarking-Study.pdf (Accessed 16 April 2020).

Holub, M. and Johnson, J. (2018) 'Bitcoin research across disciplines', The information society, Vol. 34, No. 2, pp.114-126.

Hu, Y., Valera, H.G.A. and Oxley, L (2019) 'Market efficiency of the top market-cap cryptocurrencies: Further evidence from a panel framework', Finance Research Letters, Vol. 31, pp.138-145.

Huang, J. Z., Huang, W. and Ni, J. (2018) 'Predicting Bitcoin returns using highdimensional technical indicators', Journal of Finance and Data Science. https://doi.org/10.1016/j.jfds.2018.10.001 (Accessed 14 April 2020).

Iansiti, M. and Lakhani, K.R. (2017) 'The truth about blockchain', Harvard Business Review, January-February. https://hbr.org/2017/01/the-truth-about-blockchain (Accessed 22 June 2020).

Irrera, A. (2020) 'Exclusive: JPMorgan in talks to merge blockchain unit Quorum with startup ConsenSys - sources', Reuters, February 11. [online]. https://www.reuters.com/article/us-jp-morgan-blockchain-exclusive/exclusivejpmorgan-in-talks-to-merge-blockchain-unit-quorum-with-startup-consensys-sourcesidUSKBN2051AW.

Jang, H. and Lee, J. (2018) 'An empirical study on modeling and prediction of Bitcoin prices with Bayesian Neural Networks based on blockchain information', IEEE Access, Vol. 6, pp.5427-5437.

Jaoude, J.A. and Saade, R.G. (2019) 'Blockchain applications - usage in different domains', IEEE Access, Vol. 7, pp.45360-45381.

Ji, Q. Bouri, E., Lau, C.K.M. and Roubaud, D. (2019a) 'Dynamic connectedness and integration in cryptocurrency markets', International Review of Financial Analysis, Vol. 63, pp.257-272. 
Ji, Q., E. Bouri, D. Roubaud and L. Kristoufek (2019b) 'Information interdependence among energy, cryptocurrency and major commodity markets', Energy Economics, Vol. 81, pp.1042-1055.

Jiang, Z. and Liang, J. (2017) 'Cryptocurrency portfolio management with deep reinforcement learning', in 2017 Intelligent Systems Conference (IntelliSys), IEEE, pp.905-913.

Jiang, Y., Nie, H. and Ruan, W. (2018) 'Time-varying long-term memory in bitcoin market', Finance Research Letters, Vol. 25, pp.280-284.

Kamps, J. and Kleinberg, B. (2018) 'To the moon: defining and detecting cryptocurrency pump-and-dumps', Crime Science, Vol. 7, No. 1, pp. 18.

Kapar, B. and Olmo, J. (2019) 'An analysis of price discovery between Bitcoin futures and spot markets', Economics Letters, Vol. 74, pp.62-64.

Katsiampa, P. (2019a) 'An empirical investigation of volatility dynamics in the cryptocurrency market', Research in International Business and Finance, Vol. 50, pp.322-335.

Katsiampa, P. (2019b) 'Volatility co-movement between Bitcoin and Ether', Finance Research Letters, Vol. 30, pp.221- 227.

Katsiampa, P., Corbet, S. and Lucey, B. (2019a) 'Volatility spillover effects in leading cryptocurrencies: A BEKK-MGARCH analysis', Finance Research Letters, Vol. 29, pp.68-74.

Katsiampa, P., Corbet, S. and Lucey, B. (2019b) 'High frequency volatility co-movements in cryptocurrency markets', Journal of International Financial Markets, Institutions and Money, Vol. 62, pp.35- 52.

Katz, L. (2017) 'Bitcoin acceptance among retailers is low and getting lower', Bloomberg. [online]. https://www.bloomberg.com/news/articles/2017-07-12/bitcoin-acceptanceamong-retailers-is-low-and-getting-lower (Accessed 14 April 2020).

Kim, Y. B., Kim, J. G., Kim, W., Im, J. H., Kim, T. H., Kang, S. J. and Kim, C. H., (2016) 'Predicting Fluctuations in Cryptocurrency Transactions Based on User Comments and Replies', PloS one, Vol. 11, No. 8, e0161197.

Kobie, N. (2017) 'How much energy does Bitcoin mining really use? It's complicated', Wired. https://www.wired.co.uk/article/how-much-energy-does-bitcoin-mining-reallyuse (Accessed 14 April 2020).

Koutmos, D. (2018a) 'Bitcoin returns and transaction activity', Economics Letters, Vol. 167, pp. 81-85.

Koutmos, D. (2018b) 'Return and volatility spillovers among cryptocurrencies', Economics Letters, Vol. 173, pp.122-127.

Kristoufek, L. (2013) 'BitCoin meets Google Trends and Wikipedia: Quantifying the relationship between phenomena of the Internet era', Scientific Reports, Vol. 3, No. 3415 .

Kristoufek, L., (2015) 'What are the main drivers of the Bitcoin price? Evidence from wavelet coherence analysis', PLoS one, Vol. 10, No. 4, e0123923. 
Kristoufek, L. (2018) 'On bitcoin markets (in)efficiency and its evolution', Physica A: Statistical Mechanics and its Applications, Vol. 503, pp.257-262.

Kristoufek, L. and Vosvrda, M. (2019) 'Cryptocurrencies market efficiency ranking: Not so straightforward', Physica A: Statistical Mechanics and its Applications, Vol. 531, 120853.

Kshetri, N. (2017) 'Will blockchain emerge as a tool to break the poverty chain in the Global South?', Third World Quarterly, Vol. 38, No. 8, pp.1710-1732.

Küfeoğlu, S. and Özkuran, M. (2019) 'Bitcoin mining: A global review of energy and power demand', Energy Research \& Social Science, Vol. 58, 101273.

Kumar, A. S. and Anandarao, S. (2019) 'Volatility spillover in crypto-currency markets: Some evidences from GARCH and wavelet analysis', Physica A: Statistical Mechanics and its Applications, Vol. 524, pp.448-458.

Kyriazis, N.A. (2019) 'A survey on efficiency and profitable trading opportunities in cryptocurrency markets', Journal of Risk and Financial Management, Vol. 12, No. 2, pp.67.

Kyriazis, N.A. and Prassa, P. (2019) 'Which cryptocurrencies are mostly traded in distressed times?', Journal of Risk and Financial Management, Vol. 12, No. 3, pp.135.

Lahmiri, S. and Bekiros, S. (2019) 'Cryptocurrency forecasting with deep learning chaotic neural networks', Chaos, Solitons \& Fractals, Vol. 118, pp.35-40.

Lannquist, A. (2020) 'Central Bank/Macroeconomics CBDC and DLT Research List', World Economic Forum, Centre for the Fourth Industrial Revolution [online] https://docs.google.com/document/d/1c8iGtoG7BkPriufnIPELEWvtZiNtouOyJp2IYj hAEY/edit\# (Accessed 14 April 2020).

Laboure, M. and Reid, J. (2020a) 'Part II. Moving to digital wallets and the extinction of plastic cards'. In The Future of Payments, Corporate Bank Research, Deutsche Bank, January 2020. $\quad$ https://www.dbresearch.com/PROD/RPS_ENPROD/Corporate_Bank_Research/PROD0000000000500284.alias

Laboure, M. and Reid, J. (2020b) 'Part III. Digital currencies: the ultimate hard power tool'. In The Future of Payments, Corporate Bank Research, Deutsche Bank, January $2020 . \quad$ https://www.dbresearch.com/PROD/RPS_ENPROD/Corporate_Bank_Research/PROD0000000000500284.alias

Le Tran, V. and Leirvik, T. (2019) 'Efficiency in the markets of crypto-currencies', Finance Research Letters. https://doi.org/10.1016/j.frl.2019.101382 (Accessed 14 April 2020).

Li, X. and Wang, C.A. (2017) 'The technology and economic determinants of cryptocurrency exchange rates: The case of Bitcoin', Decision Support Systems, Vol. 95, pp. 49-60.

Li, J., Li, N., Peng, J., Cui, H. and Wu, Z. (2019) 'Energy consumption of cryptocurrency mining: A study of electricity consumption in mining cryptocurrencies', Energy, Vol. 168, pp.160-168. 
Libra Association (2019) An introduction to Libra: white paper. https://libra.org/enUS/wp-content/uploads/sites/23/2019/06/LibraWhitePaper_en_US.pdf (Accessed 14 April 2020).

Liu, R., Wan, S., Zhang, Z. and Zhao, X. (2019) 'Is the introduction of futures responsible for the crash of Bitcoin?' Finance Research Letters. https://doi.org/10.1016/j.frl.2019.08.007 (Accessed 14 April 2020).

Lootsma, Y. (2017) Blockchain as the newest regtech application - the opportunity to reduce the burden of KYC for financial institutions. Banking \& Financial Services Policy Report, Vol. 36, No. 8, pp.16-21.

Madan, I., Saluja, S. and Zhao, A. (2015) Automated Bitcoin trading via machine learning algorithms. [online] http://cs229.stanford.edu/proj2014/Isaac\%20Madan,\%20Shaurya\%20Saluja,\%20Aoji a\%20Zhao,Automated\%20Bitcoin\%20Trading\%20via\%20Machine\%20Learning \%20 Algorithms.pdf (Accessed 14 April 2020).

Makarov, I. and Schoar, A. (2019) 'Trading and arbitrage in cryptocurrency markets', Journal of Financial Economics, Vol. 135, No. 2, pp.293-319.

Mallqui, D.C. and Fernandes, R.A. (2019) 'Predicting the direction, maximum, minimum and closing prices of daily Bitcoin exchange rate using machine learning techniques' Applied Soft Computing, Vol. 75, pp.596-606.

Marian, O. (2013) 'Are cryptocurrencies super tax havens', Michigan Law Review First Impressions, Vol. 112, No. 1, pp.38-48.

Masiak, C., Block, J. H., Masiak, T., Neuenkirch, M. and Pielen, K. N. (2019) 'Initial coin offerings (ICOs): Market cycles and relationship with bitcoin and ether', Small Business Economics. http://dx.doi.org/10.1007/s11187-019-00176-3 (Accessed 14 April 2020).

McNally, S., Roche, J. and Caton, S. (2018) 'Predicting the price of Bitcoin using Machine Learning' in 2018 26th Euromicro International Conference on Parallel, Distributed and Network-based Processing (PDP), IEEE, pp.339-343. https://ieeexplore.iee.org/abstract/document/8374483 (Accessed 14 April 2020).

Merediz-Sola, I., and Bariviera, A. F. (2019) 'A bibliometric analysis of bitcoin scientific production'. Research in International Business and Finance, Vol. 50, pp.294-305.

Migliardi, M., Merlo, A. and Passaglia, A. (2015) 'On the feasibility of moderating a peerto-peer CDN system: A proof-of-concept implementation'. In Proceedings of the 10th International Conference on P2P, Parallel, Grid, Cloud, and Internet Computing (3PGCIC), IEEE, pp.689-694. http://dx.doi.org/10.1109/3PGCIC.2015.53 (Accessed 22 June 2020).

Miller, N., Yang, Y., Sun, B. and Zhang, G. (2019) 'Identification of technical analysis patterns with smoothing splines for bitcoin prices', Journal of Applied Statistics, Vol. 46, No. 12, pp.2289-2297.

Monetary Authority of Singapore (2017) The future is here - Project Ubin: SGD on distributed ledger, Deloitte, Monetary Authority of Singapore. https://www.mas.gov.sg/-/media/MAS/ProjectUbin/Project-Ubin--SGD-onDistributed-Ledger.pdf (Accessed 14 April 2020). 
Mohanta, B.K., Jena, D., Panda, S.S. and Sobhanayak, S. (2019) 'Blockchain technology: A survey on applications and security privacy challenges' Internet of Things, Vol. 8, 100107.

Monrat, A.A., Schelén, O. and Andersson, K. (2019) 'A survey of blockchain from the perspectives of applications, challenges, and opportunities', IEEE Access, Vol. 7, pp.117134-117151.

Mora, C., Rollins, R.L., Taladay, K., Kantar, M.B., Chock, M.K., Shimada, M. and Franklin, E.C. (2018) 'Bitcoin emissions alone could push global warming above 2 degree', Nature Climate Change, Vol. 8, pp.931-933.

Morhaim, L. (2019) 'Blockchain and cryptocurrencies technologies and network structures: applications, implications and beyond', CRED Working Paper, No. 201924, CRED - Université Paris II. https://hal.archives-ouvertes.fr/hal-02280279/ (Accessed 16 April 2020).

Mougayar, W. (2016) The Business Blockchain: Promise, Practice, and Application of the Next Internet Technology, Hoboken, NJ: John Wiley Sons, Inc.

Murphy, H. and Yang, Y. (2020) 'Patents reveal extent of China's digital currency plans', Financial Times, 13 February. https://www.ft.com/content/f10e94cc-4d74-11ea-95a0$\underline{43 \mathrm{~d} 18 \mathrm{ec} 715 \mathrm{f} 5}$ (Accessed 12 April 2020).

Narayanan, A., Bonneau, J., Felten, E., Miller, A. and Goldfeder, S. (2016) Bitcoin and cryptocurrency technologies: A comprehensive introduction, Princeton University Press.

Narayanan, A. and Clark, J. (2017) 'Bitcoin's academic pedigree', Communications of the $A C M$, Vol. 60, No. 12, pp. 36-45.

Nadarajah, S. and Chu, J. (2017) 'On the inefficiency of bitcoin', Economics Letters, Vol. 150, pp.6-9.

Nakamoto, S. (2008) 'Bitcoin: A peer-to-peer electronic cash system'. https://Bitcoin.org/Bitcoin.pdf (Accessed 12 April 2020).

Nakano, M., Takahashi, A. and Takahashi, S. (2018) 'Bitcoin technical trading with artificial neural network', Physica A: Statistical Mechanics and its Applications, Vol. 510, pp.587-609.

Nelson, B. (2018) 'Financial stability and monetary policy issues associated with digital currencies', Journal of Economics and Business, Vol. 100, pp.76-78.

Niepelt, D. (2016) 'Central banking and Bitcoin: not yet a threat'. Vox CEPR's policy portal-research-based policy analysis and commentary from leading economists. [online]. $\quad$ https://voxeu.org/article/central-banking-and-bitcoin-not-yet-threat (Accessed 25 June 2020)

Niepelt, D. (2018) 'Reserves for all? Central bank digital currency, deposits, and their (non)-equivalence', International Journal of Central Banking, June. https://www.ijcb.org/journal/ijcb20q2a6.htm (Accessed 26 June 2020).

O'Dwyer K.J and Malone D. (2014) 'Bitcoin mining and its energy footprint', in 25th IETirish signals systems conference 2014 and 2014 China-Ireland international 
conference on information and communications technologies (ISSC 2014/CIICT2014), pp.280-285.

Omane-Adjepong, M. and Alagidede, I.P. (2019) 'Multiresolution analysis and spillovers of major cryptocurrency markets', Research in International Business and Finance, Vol. 49, pp.191-206.

Pagnottoni, P. and Dimpfl, T. (2019) 'Price discovery on Bitcoin markets', Digital Finance, Vol. 1, No. 1-4, pp.139-161.

Phillips, R.C. and Gorse, D. (2017) 'Predicting cryptocurrency price bubbles using social media data and epidemic modelling' 2017 IEEE Symposium Series on Computational Intelligence (SSCI), pp.1-7.

Phillips R.C. and Gorse, D. (2018) 'Cryptocurrency price drivers: Wavelet coherence analysis revisited', PLoS one, Vol. 13, No. 4, e0195200.

Pieters, G.C. (2017) The potential impact of decentralized virtual currency on monetary Policy, Federal Reserve Bank of Dallas - Globalization and Monetary Policy Institute 2016 Annual Report. https://ssrn.com/abstract=2976515 (Accessed 26 June 2020)

Pieters, G.C. and Vivanco, S. (2017) 'Financial regulations and price inconsistencies across Bitcoin markets', Information Economics and Policy, Vol. 39, pp.1-14.

Polasik, M., Piotrowska, A.I., Wisniewski, T.P., Kotkowski, R. and Lightfoot, G. (2015) 'Price fluctuations and the use of Bitcoin: An empirical inquiry', International Journal of Electronic Commerce, Vol. 20, No. 1, pp.9-49.

Raskin, M. and Yermack, D. (2018) 'Digital currencies, decentralized ledgers and the future of central banking'. In Research Handbook on Central Banking, Ch 22, Edward Elgar Publishing.

Rauchs, M., Blandin, A., Klein, K., Pieters, G.C., Recanatini, M. and Zhang, B. Z. (2018) 2nd Global Cryptoasset Benchmarking Study, University of Cambridge, Cambridge Center for Alternative Finance.

Ryan, P.A. (2017) 'Smart contract relations in e-commerce: legal implications of exchanges conducted on the blockchain', Technology Innovation Management Review, Vol. 7, No. 1, pp.10-17.

Schmeling, M. (2019), 'What is Libra? Understanding Facebook's currency', SAFE Policy Letter, No. 76, Goethe University Frankfurt, SAFE - Sustainable Architecture for Finance in Europe, Frankfurt a. https://www.econstor.eu/bitstream/10419/204501/1/167792165X.pdf （Accessed 14 April 2020).

Scott, J.Z. (2018) 'Is China about to launch its own cryptocurrency?', World Economic Forum, 15 October. https://www.weforum.org/agenda/2018/10/is-china-about-tolaunch-its-own-cryptocurrency/ (Accessed 14 April 2020).

Sebastião, H., Duarte, A.P. and Guerreiro, G. (2017) 'Where is the Information on USD/Bitcoin Hourly Prices?', Notas Económicas, Vol. 45, pp.7-25.

Sebastião, H. and Godinho, P. (2019) 'Bitcoin futures: An effective tool for hedging cryptocurrencies', Finance Research Letters. https://doi.org/10.1016/j.frl.2019.07.003 (Accessed 14 April 2020). 
SEC (2017) 'Investor bulletin: Initial Coin Offerings', Investor Alerts and Bulletins 25 July. [online]. https://www.sec.gov/oiea/investor-alerts-and-bulletins/ib_coinofferings (Accessed 14 April 2020)

Selgin, G. (2015) 'Synthetic commodity money', Journal of Financial Stability, Vol. 17, pp.92-99.

Smales, L. A. (2019) 'Bitcoin as a safe haven: Is it even worth considering?', Finance Research Letters, Vol. 30, pp.385-393.

Statt, N. (2020) 'Facebook is shifting its Libra cryptocurrency plans after intense regulatory pressure', The Verge. https://www.theverge.com/2020/3/3/21163658/facebook-libracryptocurrency-token-ditching-plans-calibra-wallet-delay (Accessed 14 April 2020).

Stavroyiannis, S. and Babalos, V. (2019) 'Herding behavior in cryptocurrencies revisited: Novel evidence from a TVP model', Journal of Behavioral and Experimental Finance, Vol. 22, pp.57-63.

Subramanian, H. (2017) 'Decentralized blockchain-based electronic marketplaces', Communications of the ACM, Vol. 61, 1, pp.78-84.

Sveriges Riksbank (2017) The Riksbank's e-krona project, Report 1. https://www.riksbank.se/en-gb/payments--cash/e-krona/e-krona-reports/e-kronaproject-report-1/ (Accessed 14 April 2020).

Sveriges Riksbank (2018) The Riksbank's e-krona project, Report 2. https://www.riksbank.se/globalassets/media/rapporter/e-krona/2018/the-riksbanks-ekrona-project-report-2.pdf (Accessed 14 April 2020).

Sveriges Riksbank (2019) Payments in Sweden 2019. https://www.riksbank.se/globalassets/media/rapporter/sa-betalarsvenskarna/2019/engelska/payments-in-sweden-2019.pdf (Accessed 14 April 2020).

Swan, M. (2015) Blockchain. Blueprint for a New Economy, CA: O'Reilly, Sebastopol.

Symitsi, E. and Chalvatzis, K. (2018) 'Return, volatility and shock spillovers of Bitcoin with energy and technology companies', Economics Letters, Vol. 170, pp.127-130.

Szabo, N. (1994). Smart contracts. [online]. https://www.fon.hum.uva.nl/rob/Courses/InformationInSpeech/CDROM/Literature/L OTwinterschool2006/szabo.best.vwh.net/smart.contracts.html (Accessed 22 June 2020).

Szabo, N. (1997) 'Formalizing and securing relationships on public networks', First Monday, Vol. 2, No. 9. https://doi.org/10.5210/fm.v2i9.548

Taylor, P. J., Dargahi, T., Dehghantanha, A., Parizi, R.M., and Choo, K.K.R. (2019) 'A systematic literature review of blockchain cyber security', Digital Communications and Networks. https://doi.org/10.1016/j.dcan.2019.01.005 (Accessed 14 April 2020).

Teichmann, F. (2018) 'Financing terrorism through cryptocurrencies - a danger for Europe?', Journal of Money Laundering Control, Vol. 21, No. 4, pp. 513-519.

Thakor, A.V. (2020) 'Fintech and banking: What do we know?', Journal of Financial Intermediation, Vol. 41. https://doi.org/10.1016/j.jfi.2019.100833. 
Tiwari, A.K., Jana, R.K., Das, D. and Roubaud, D. (2018) 'Informational efficiency of Bitcoin - An extension', Economics Letters, Vol. 163, pp.106-109.

Tiwari, A. K., Adewuyi, A. O., Albulescu, C. T., and Wohar, M. E. (2019) 'Empirical evidence of extreme dependence and contagion risk between main cryptocurrencies', The North American Journal of Economics and Finance, 101083.

Truby, J. (2018) 'Decarbonizing Bitcoin: Law and policy choices for reducing the energy consumption of Blockchain technologies and digital currencies' Energy research \& social science, Vol. 44, pp.399-410.

Tzouvanas, P., Kizys, R. and Tsend-Ayush, B. (2019) 'Momentum trading in cryptocurrencies: Short-term returns and diversification benefits', Economics Letters. https://doi.org/10.1016/j.econlet.2019.108728 (Accessed 14 April 2020).

Urquhart, A. (2016) 'The inefficiency of Bitcoin', Economics Letters, Vol. 148, pp.80-82.

Urquhart, A. and Zhang, H. (2019) 'Is Bitcoin a hedge or safe haven for currencies? An intraday analysis', International Review of Financial Analysis, Vol. 63, pp.49-57.

Vidal-Tomás, D. and Ibañez, A. (2018) 'Semi-strong efficiency of Bitcoin', Finance Research Letters, Vol. 27, pp.259-265.

Vidal-Tomás, D., Ibáñez, A. M. and Farinós, J. E. (2019) 'Herding in the cryptocurrency market: CSSD and CSAD approaches', Finance Research Letters, Vol. 30, pp.181-186.

Vo, A. and Yost-Bremm, C. (2018) 'A high-frequency algorithmic trading strategy for cryptocurrency', Journal of Computer Information Systems, pp.1-14. https://doi.org/10.1080/08874417.2018.1552090 (Accessed 14 April 2020).

Vranken, H. (2017) 'Sustainability of bitcoin and blockchains', Current opinion in environmental sustainability, Vol. 28, pp.1-9.

Wahab, A. and Mehmood, W. (2018) 'Survey of consensus protocols', arXiv preprint, arXiv:1810.03357. https://arxiv.org/abs/1810.03357 (Accessed 16 April 2020).

Wang, W., Hoang, D. T., Hu, P., Xiong, Z., Niyato, D., Wang, P., Wen, Y. and Kim, D.I. (2019a) 'A survey on consensus mechanisms and mining strategy management in blockchain networks', IEEE Access, Vol. 7, pp.22328-22370.

Wang, P., Zhang, W., Li, X. and Shen, D. (2019) 'Trading volume and return volatility of Bitcoin market: evidence for the sequential information arrival hypothesis', Journal of Economic Interaction and Coordination, Vol. 14, No. 2, pp.377-418.

Wegberg, R.S., Oerlemans, J. and Deventer, O.V. (2018) 'Bitcoin money laundering: mixed results? An explorative study on money laundering of cybercrime proceeds using bitcoin', Journal of Financial Crime, Vol. 25, 17.

Wei, W.C. (2018) 'Liquidity and market efficiency in cryptocurrencies', Economics Letters, Vol. 168, pp.21-24.

WEF (2015) Deep Shift Technology Tipping Points and Societal Impact, Survey Report. World Economic Forum https://www.weforum.org/reports/deep-shift-technologytipping-points-and-societal-impact (Accessed 14 April 2020).

WEF(2019) Central banks and distributed ledger technology: How are central banks exploring blockchain today?, World Economic Forum. 
http://www3.weforum.org/docs/WEF_Central_Bank_Activity_in_Blockchain_DLT.p df (Accessed 14 April 2020).

Xiaolei, S, Mingxi, L. and Zeqian, S. (2018) 'A novel cryptocurrency price trend forecasting model based on LightGBM', Finance Research Letters. Vol. 32, 101084.

Xu, M., Chen, X. and Kou, G. (2019) 'A systematic review of blockchain', Financial Innovation, Vol. 5, No. 1, 27.

Xuanmin, L. (2020) 'China's central bank moves closer to issuing digital currency: insiders', Global Times. https://www.globaltimes.cn/content/1183579.shtml (Accessed 14 April 2020).

Yaga, D., Mell, P., Roby, N., \& Scarfone, K. (2019) 'Blockchain technology overview', arXiv preprint, arXiv:1906.11078. https://arxiv.org/abs/1906.11078 (Accessed 16 April 2020).

Yang, W., Aghasian, E., Garg, S., Herbert, D., Disiuta, L. and Kang, B. (2019) 'A Survey on blockchain-based internet service architecture: Requirements, challenges, trends and future', IEEE Access, Vol. 7, 75845- 75872.

Yermack, D. (2015) 'Is Bitcoin a real currency? An economic appraisal', in Handbook of Digital Currency (pp.31-43). Academic Press.

Yi, S., Xu, Z. and Wang, G.J. (2018) 'Volatility connectedness in the cryptocurrency market: Is Bitcoin a dominant cryptocurrency?', International Review of Financial Analysis, Vol. 60, pp.98-114.

Zargar, F.N. and Kumar, D. (2019) 'Informational inefficiency of Bitcoin: A study based on high-frequency data', Research in International Business and Finance, Vol. 47, pp.344-353.

Zheng, Z., Xie, S., Dai, H., Chen, X. and Wang, H. (2017) 'An overview of blockchain technology: Architecture, consensus, and future trends', in 2017 IEEE International Congress on Big Data (BigData Congress), IEEE, pp.557-564.

Zhang, Y., Chan, S., Chu, J. andNadarajah, S. (2019) 'Stylised facts for high frequency cryptocurrency data', Physica A: Statistical Mechanics and its Applications, Vol. 513, pp.598-612.

Zhu, Y., Dickinson, D. and Li, J. (2017) 'Analysis on the influence factors of Bitcoin's price based on VEC model', Financial Innovation, Vol. 3, No. 3, pp.1-13.

Żbikowski, K. (2016) 'Application of machine learning algorithms for bitcoin automated trading', in Machine Intelligence and Big Data in Industry, Springer, Cham, pp.161168.

Zieba, D., Kokoszczynski, R. and Sledziewska, K. (2019) 'Shock transmission in the cryptocurrency market. Is Bitcoin the most influential?', International Review of Financial Analysis, Vol. 64, pp.102-125. 